Portland State University

PDXScholar

Civil and Environmental Engineering

Undergraduate Honors Theses

Spring 2021

\title{
CEI Hub Failure Following a Cascadia Earthquake Event: Preliminary Modeling of a Liquid Fuel Spill in the Lower Willamette and Columbia Rivers
}

Mike Du Bose

Portland State University

Follow this and additional works at: https://pdxscholar.library.pdx.edu/cengin_honorstheses

Part of the Hydraulic Engineering Commons

Let us know how access to this document benefits you.

\section{Recommended Citation}

Du Bose, Mike, "CEI Hub Failure Following a Cascadia Earthquake Event: Preliminary Modeling of a Liquid Fuel Spill in the Lower Willamette and Columbia Rivers" (2021). Civil and Environmental Engineering Undergraduate Honors Theses. 14.

https://doi.org/10.15760/honors.1146

This Thesis is brought to you for free and open access. It has been accepted for inclusion in Civil and Environmental Engineering Undergraduate Honors Theses by an authorized administrator of PDXScholar. Please contact us if we can make this document more accessible: pdxscholar@pdx.edu. 


\section{Portland State \\ U N I VERSITY}

Department of Civil and Environmental Engineering Honors

\section{CEI Hub failure following a Cascadia earthquake event: Preliminary modeling of a liquid fuel spill in the Lower Willamette and Columbia Rivers}

June 2021

CEE Honors Thesis by

Mike Du Bose

Honors Advisor

Dr. Scott A. Wells 


\begin{abstract}
The Critical Energy Infrastructure (CEI) Hub in Northwest Portland, OR spans a six-mile stretch of the Lower Willamette River and stores $90 \%$ of Oregon's liquid fuel supply and $100 \%$ of the jet fuel for PDX. The CEI Hub is also built entirely on liquefiable soils which are likely to fail during a Cascadia earthquake event. The purpose of this project was to model a liquid fuel spill in the Lower Willamette and Columbia Rivers using the CE-QUAL-W2 model. Several scenarios were developed to account for different environmental conditions, (e.g., high and low discharge years) and varying spill durations (e.g., rapid or prolonged). Fuel concentrations were analyzed near Portland and the downstream towns of St. Helens and Rainier, OR to assess potential impacts of a liquid fuel spill on communities along the affected rivers. Further water quality analysis using EPA standards was performed for Rainier since the town relies on Columbia River surface water as a drinking water source. Model limitations and refinements were also discussed for future fuel spill analysis on this river system.
\end{abstract}

\title{
Acknowledgements
}

Scott Wells for guidance and support throughout the development and completion of this CEE Department Honors Thesis.

Chris Berger for providing the CE-QUAL-W2 Lower Willamette River model and technical support.

Evan Kristof and Kiley Melicker for helping me navigate the departmental requirements for the CEE Honors Program.

Becca Pierpont for the invaluable writing feedback, and unwavering patience and support through this process. 


\section{Contents}

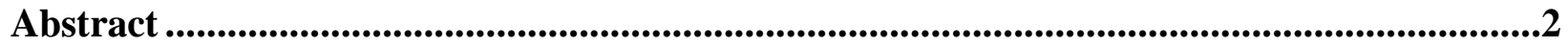

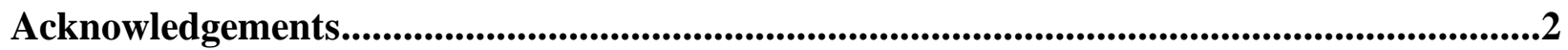

List of Figures.......................................................................................................................................4

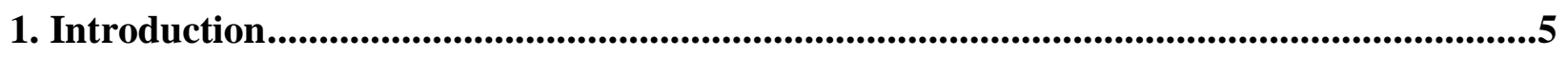

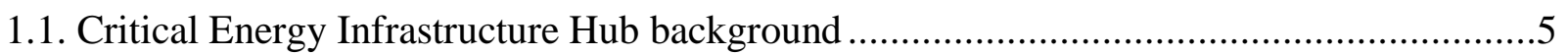

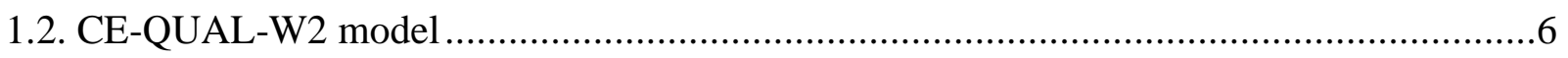

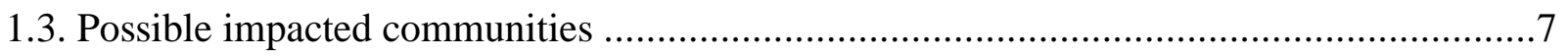

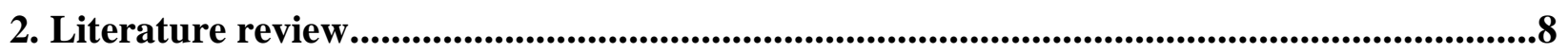

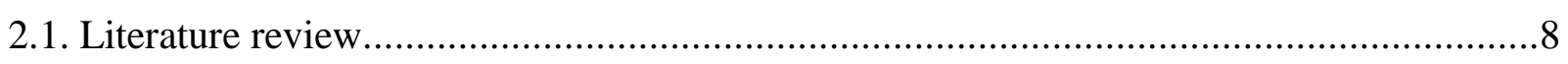

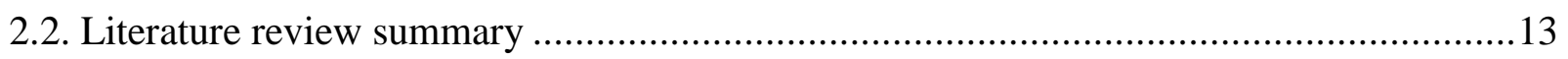

3 CE-QUAL-W2 model..................................................................................................................14

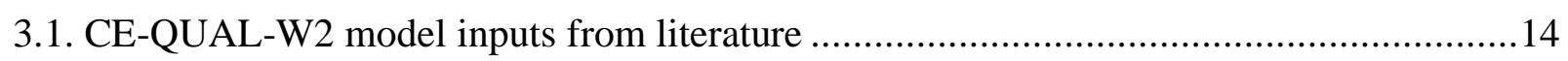

3.2. Simplifying assumptions for CE-QUAL-W2 model inputs............................................15

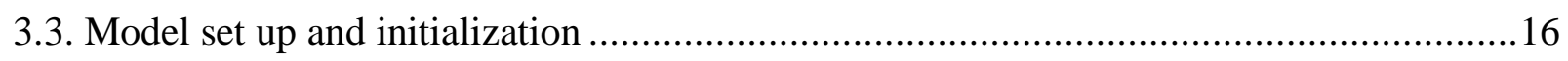

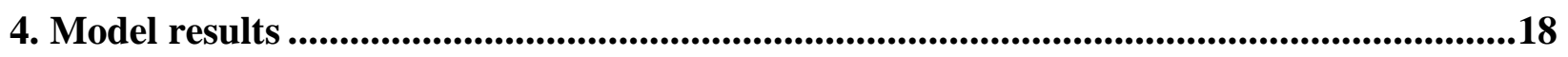

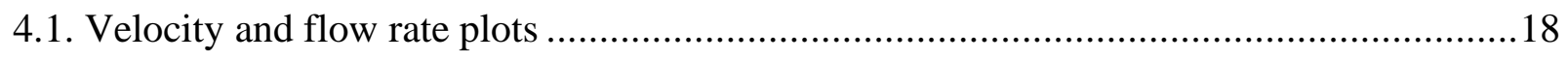

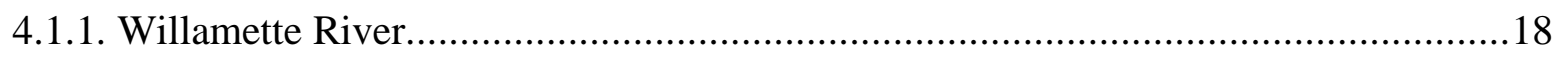

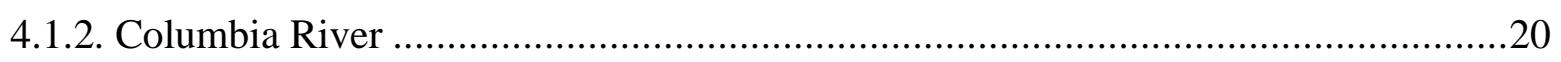

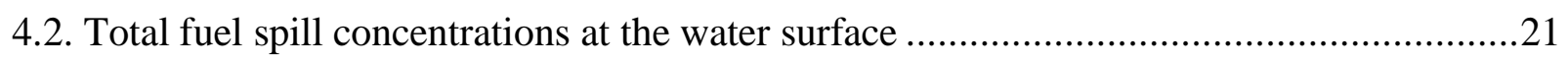

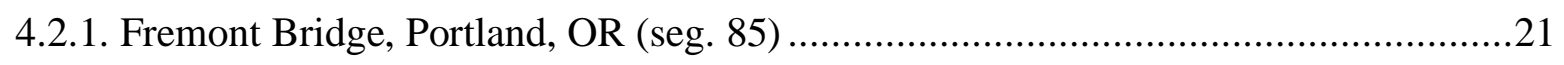

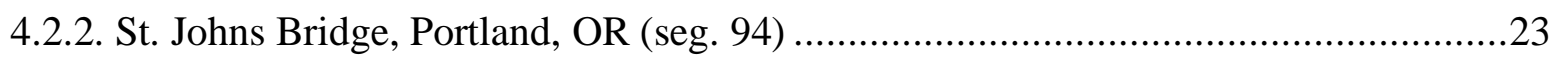

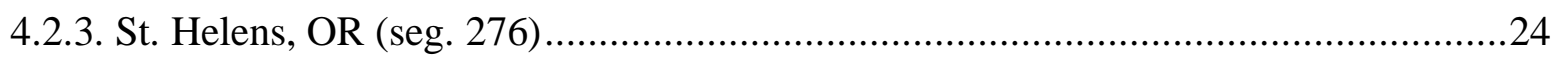

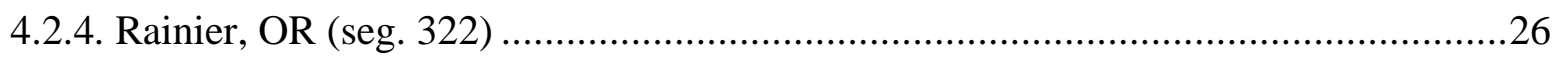

4.2.5. Beaver Army Terminal (model terminus; seg. 356) ..................................................28

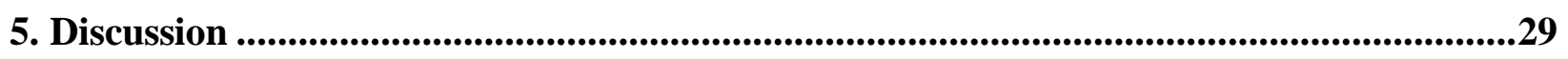

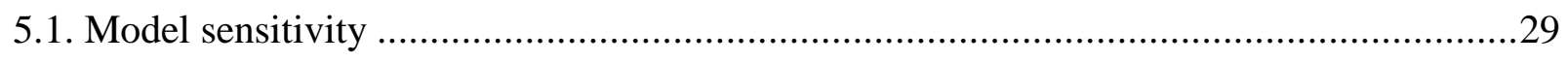

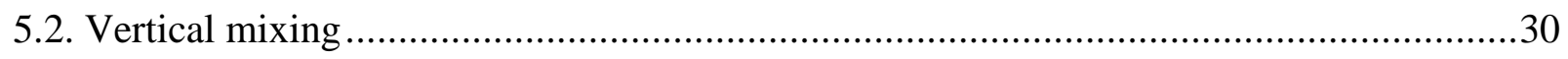

5.3. Water quality at Rainier, OR (seg. 322).....................................................................

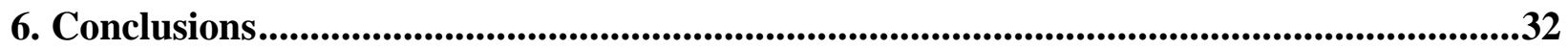

References.................................................................................................................................................34 


\section{List of Figures}

Figure 1: Outline of the Critical Energy Infrastructure (CEI) Hub in northwest Portland, OR along the Lower Willamette River (OSSPAC, 2019; Google Maps, 2019)..............................6 Figure 2: CE-QUAL-W2 Willamette and Columbia River model areas, including tributaries and boundaries (Berger et al., 2001).................................................................................

Figure 3: Liquid fuel slick transformation in rivers (modified from Shen and Yapa, 1988).......14

Figure 4: Model segment numbers in the Lower Willamette River near the CEI Hub and downtown Portland (Berger et al., 2001)................................................................ 17

Figure 5: Surface velocity at the Fremont Bridge (seg. 85) .................................................. 19

Figure 6: Flow rate at the Fremont Bridge (seg. 85) ..................................................... 19

Figure 7: Surface velocity at Rainier, OR (seg. 322) ..........................................................20

Figure 8: Flow rate at Rainier, OR (seg. 322). ............................................................21

Figure 9: 1-hour spill duration at the Fremont Bridge (upstream; seg. 85) in the Willamette

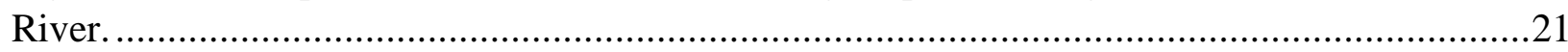

Figure 10: 1-day spill duration at the Fremont Bridge (upstream; seg. 85) in the Willamette River. ..............................................................................................................22

Figure 11: 1-week spill duration at the Fremont Bridge (upstream; seg. 85) in the Willamette

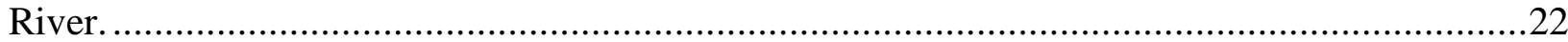

Figure 12: 1-hour spill duration at the St. Johns Bridge (immediately downstream; seg. 94) in the Willamette River. .23

Figure 13: 1-day spill duration at the St. Johns Bridge (immediately downstream; seg. 94) in the Willamette River.

Figure 14: 1-week spill duration at the St. Johns Bridge (immediately downstream; seg. 94) in the Willamette River. .........................................................................................24

Figure 15: 1-hour spill duration at St. Helens, OR (seg. 276) in the Columbia River.................25

Figure 16: 1-day spill duration at St. Helens, OR (seg. 276) in the Columbia River.................25

Figure 17: 1-week spill duration at St. Helens, OR (seg. 276) in the Columbia River................26

Figure 18: 1-hour spill duration at Rainier, OR (seg. 322) in the Columbia River.....................26

Figure 19: 1-day spill duration at Rainier, OR (seg. 322) in the Columbia River......................27

Figure 20: 1-week spill duration at Rainier, OR (seg. 322) in the Columbia River....................27

Figure 21: 1-hour spill duration at Beaver Army Terminal (seg. 356), near Quincy, OR, in the Columbia River.............................................................................................28

Figure 22: 1-day spill duration at Beaver Army Terminal (seg. 356), near Quincy, OR, in the

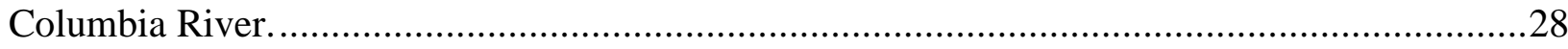

Figure 23: 1-week spill duration at Beaver Army Terminal (seg. 356), near Quincy, OR, in the

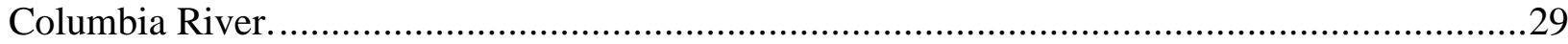

Figure 24: Plan view of the modeled system for the 1-day spill duration, Julian day 202.0 (5 days

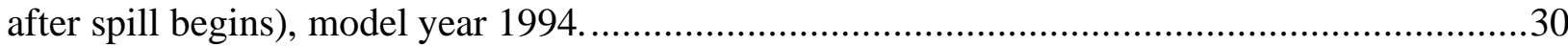
Figure 25: Profile view of Willamette River model (branch 2) for the 1-day spill duration on Julian Day 203 (6 days after spill begins), model year 1994. 


\section{Introduction}

The Pacific Northwest is expected to experience a periodic, massive earthquake called the Cascadia Subduction Zone earthquake event. The Cascadia Subduction Zone is approximately 100 miles off the west coast of North America in the Pacific Ocean. It spans 600 miles from British Columbia to northern California and is a geological fault where the Explorer, Juan De Fuca, and Gorda faults meet. The fault ruptures periodically resulting in the Cascadia event $-\mathrm{a}$ magnitude 8-9 earthquake - which is predicted to occur in the next 50 years with a $37 \%$ likelihood (Goldfinger et al., 2012). All infrastructure in the potentially affected region was constructed after the last Cascadia event, January 1700, and non-Native knowledge of the periodic occurrence has only been established over the last few decades (Wang et al., 2013).

Most of the energy infrastructure in the region was constructed using older building codes before seismic resilience was required, including the Critical Energy Infrastructure (CEI) Hub in Portland, OR (Wang et al., 2013). A Cascadia event would likely result in catastrophic structural failure in most, or all, of the liquid fuel storage tanks at the CEI Hub whereupon the fuel will spill directly into the Lower Willamette River and flow into the Columbia River.

The purpose of this report was to model a liquid fuel spill from the CEI Hub into the Lower Willamette River using the CE-QUAL-W2 model. It includes a literature review to determine spill characteristics, fate and transport, volatile and non-volatile constituents, and to analyze previous modeling results to identify parameters and inputs applicable to the CE-QUAL-W2 model of the Willamette and Columbia Rivers.

\subsection{Critical Energy Infrastructure Hub background}

The Critical Energy Infrastructure (CEI) Hub in Northwest Portland, OR spans a six-mile stretch of the lower Willamette River (Figure 1). The Hub is located near three major earthquake faults - the Oatfield Fault, the Portland Hills Fault, and the East Bank Fault - and abuts the Portland Hills Fault. The entire CEI Hub was constructed on liquefiable soils which are expected to fail in the event of a Cascadia Subduction Zone earthquake event. There are 46 large above-ground liquid fuel storage tanks in the hub ranging from over 100 to 15 years old with the majority at least 50 years old (OSSPAC, 2019). None of the tanks were designed for seismic resiliency and similar facilities have been damaged or destroyed in past earthquakes. The CEI facilities and infrastructure are owned by twelve different companies and store $90 \%$ of Oregon's liquid fuel supply and $100 \%$ of the jet fuel for the Portland International Airport (Wang et al., 2013). The fuel companies are not required to report types of fuel stored and few have reported voluntarily. Based on the findings of Oregon Public Broadcasting's Tony Schick and referenced in the Oregon Seismic Safety Policy Advisory Committee report (2019) there are 118.2M gal. of gasoline, 59.4M gal. of diesel, 17.9M gal. of aviation fuel, 53.8M gal of unspecified liquid petroleum (including Alberta tar sands oil), 24.3M gal. of asphalt, and 14.9M gal. unused. When the Cascadia event occurs, it is likely that most, if not all, of those fuel stores will spill into the Willamette River which feeds into the Columbia River. 


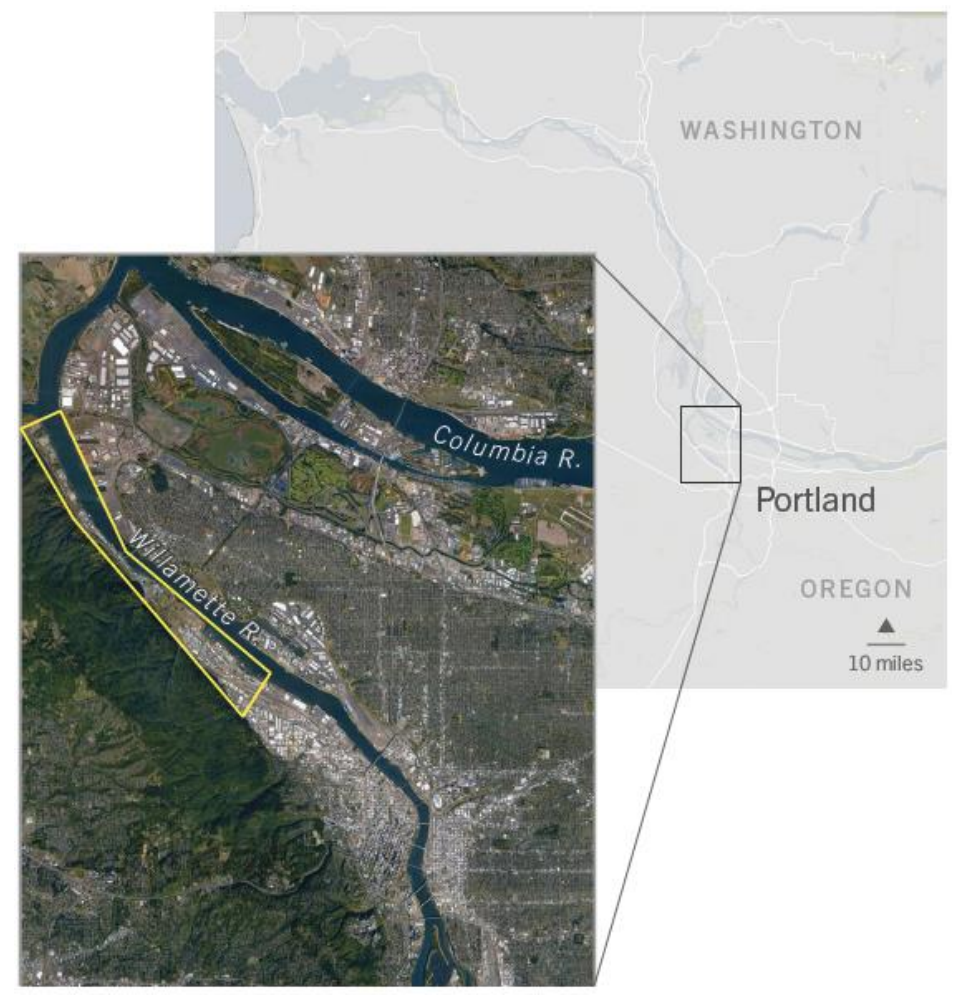

Figure 1: Outline of the Critical Energy Infrastructure (CEI) Hub in northwest Portland, OR along the Lower Willamette River (OSSPAC, 2019; Google Maps, 2019).

\subsection{CE-QUAL-W2 model}

CE-QUAL-W2 is a 2-dimensional (longitudinal-vertical) hydrodynamic and water quality model developed by the United States Army Corps of Engineers (Wells, 2019a). The model can predict water surface, velocity, temperature, multiple generic constituents (e.g., tracers, volatiles), as well as numerous biological, physical, and chemical parameters. CE-QUAL-W2 uses coupled hydrodynamic and water quality transport models and can model branched and/or looped systems including flow and boundary conditions (Berger and Wells, 2019). The Lower Willamette River models (Figure 2) used in this study were developed and calibrated by Berger et al. (2001) using flow rate, water level, and water quality data from 1994 and 1997 using CEQUAL-W2 version 3.1, and updated to version 4.1 (Berger and Wells, 2019). Based on USGS sensor data of averaged annual discharge for the Willamette River (see Table 1), flow rates for calibration years 1997 highest while 1994 was the second lowest - nearly 3 times lower than peak discharge years - over a 30-year period. These models were used for the simulations described in this paper to account for high and low predicted advection and dilution discharge years. 


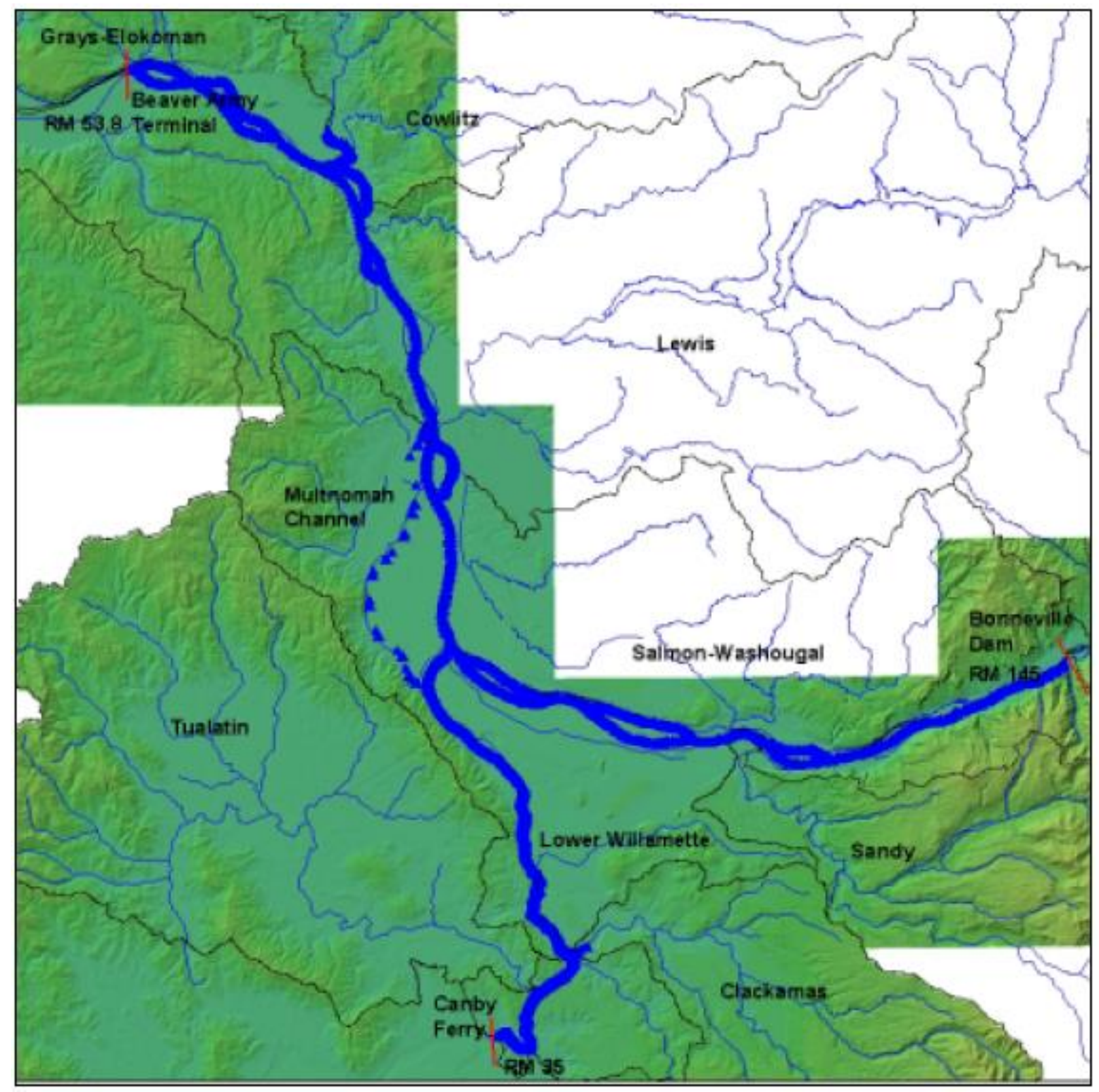

Figure 2: CE-QUAL-W2 Willamette and Columbia River model areas, including tributaries and boundaries (Berger et al., 2001).

\subsection{Possible impacted communities}

Most communities downstream of, and including, Portland will likely be impacted by a liquid fuel spill from the CEI Hub. Locations for water quality and fuel concentration analysis were selected along the Willamette River for Downtown and North/Northwest Portland (up- and downstream from the CEI Hub), and along the Columbia River for St. Helens, Rainier, and the Beaver Army Terminal, OR (the model terminus near Quincy). Portland and St. Helens do not 
Table 1: Averaged annual discharge for the Willamette River (USGS 14211720)

\begin{tabular}{|l|l|l|l|l|l|l|l|l|l|l|l|l|l|l|l|}
\hline $\begin{array}{c}\text { Water } \\
\text { Year }\end{array}$ & 1990 & 1991 & 1992 & 1993 & 1994 & 1995 & 1996 & 1997 & 1998 & 1999 & 2000 & 2001 & 2002 & 2003 & 2004 \\
\hline $\begin{array}{c}\text { Discharge, } \\
\mathrm{ft}^{3} / \mathrm{s}\end{array}$ & 26820 & 28300 & 22870 & 35590 & 20210 & 38050 & 51910 & 53760 & 34720 & 48670 & 35070 & 16020 & 34450 & 30470 & 29420 \\
\hline $\begin{array}{c}\text { Discharge, } \\
\mathrm{m}^{3} / \mathrm{s}\end{array}$ & 759 & 801 & 648 & 1008 & 572 & 1077 & 1470 & 1522 & 983 & 1378 & 993 & 454 & 976 & 863 & 833 \\
\hline \begin{tabular}{|c|c|c|c|c|c|c|c|c|c|c|c|}
\hline Water \\
Year
\end{tabular} & 2005 & 2006 & 2007 & 2008 & 2009 & 2010 & 2011 & 2012 & 2013 & 2014 & 2015 & 2016 & 2017 & 2018 & 2019 \\
\hline $\begin{array}{c}\text { Discharge, } \\
\mathrm{ft}^{3} / \mathrm{s}\end{array}$ & 20860 & 38810 & 33900 & 35090 & 28480 & 32370 & 41190 & 37910 & 30890 & 31600 & 25760 & 34270 & 43870 & 27940 & 23490 \\
\hline $\begin{array}{c}\text { Discharge, } \\
\mathrm{m}^{3} / \mathrm{s}\end{array}$ & 591 & 1099 & 960 & 994 & 806 & 917 & 1166 & 1073 & 875 & 895 & 729 & 970 & 1242 & 791 & 665 \\
\hline
\end{tabular}

depend on the Willamette or Columbia Rivers for their water supplies. However, the Columbia River is a secondary source of drinking water for Rainier (DEQ, 2000). Therefore,

Environmental Protection Agency (EPA) standards for benzene - a primary volatile constituent in most liquid fuels - concentration in drinking water supplies were considered at that location.

\section{Literature review}

Many models have been developed for crude oil spills in maritime and riverine systems. However, very few models and studies exist related to other petroleum based liquid fuel spills into those same systems. Though crude oils, including Alberta tar sands, are stored at the CEI Hub, most fuels stored are refined liquid fuels (i.e., gasoline, diesel and jet fuel).

\subsection{Literature review}

To set up the CE-QUAL-W2 model, journal articles were selected based on their relevance to modeling the types of fuels stored at the CEI Hub. Information about fuel characteristics, qualitative and quantitative descriptions of the fate and transport of those fuels in riverine systems, and other model parameters and results were summarized in Table 2.

Table 2: Literature related to modeling oil and gas spills

\begin{tabular}{|l|l|}
\hline Reference & Description of reference on modeling oil and gas spills \\
\hline Chin, J. Y., and & $\begin{array}{l}\text { All fuels measured for this study were liquid and not combusted. } \\
\text { A common commercial diesel, ultra-low sulfur diesel (ULSD), } \\
\text { was found to have a total volatile organic compound (VOC) } \\
\text { fraction of 10\% by weight. Similarly, biodiesel blends, which } \\
\text { blend ULSD and soy-based derivatives, were found to have a } \\
\text { VOC fraction of } 6 \% \text { by weight. The authors note that very few } \\
\text { studies have been published concerning VOC content in diesel } \\
\text { fuels. }\end{array}$ \\
\hline Clark et al. (1990) & $\begin{array}{l}\text { Following the } 800,000 \text { gal diesel fuel spill into Monongahela } \\
\text { River, a major tributary of the Ohio River, due to a catastrophic } \\
\text { failure of a storage tank, several models were used to determine } \\
\text { fate and transport and lasting effects of the spill. Some of the } \\
\text { findings based on lab testing of samples taken along the } \\
\text { downstream span of river over multiple days showed higher }\end{array}$ \\
\hline
\end{tabular}




\begin{tabular}{|c|c|}
\hline & $\begin{array}{l}\text { concentrations of volatiles closer to spill origin with a quick } \\
\text { reduction as the plume traveled downstream. The empirical } \\
\text { equation developed for peak concentration using QUAL-II from } \\
296 \text { runs was: } \\
\qquad \text { Peak }=0.74+0.04236 * C_{0} * e^{K * T O T}\left(R^{2}=0.93\right) \\
\qquad P e a k=\text { peak concentration }(\mu g / L) \\
\qquad C_{0}=\text { initial concentration }(\mu g / L) \\
\qquad K=\text { decay rate }(L / d) \\
\text { TOT = time of travel }(d) \\
\text { There were many challenges encountered when collecting data } \\
\left.\text { foo, } 000 \mathrm{ft}^{3} / \mathrm{s}\right) \text { as well as a freeze/thaw event. The plume passed } \\
\text { through several locks and dams mixing vertically into the water } \\
\text { column as it traveled downstream, a specific challenge that will } \\
\text { not be faced by a potential CEI Hub catastrophic failure. }\end{array}$ \\
\hline Dew et al. (2015) & $\begin{array}{l}\text { Alberta tar sands oils are high viscosity bitumen and must be } \\
\text { diluted with a variety of products to transport it via pipelines. The } \\
\text { three most common diluted products are dilbit (diluted bitumen } \\
\{70-80 \%\} \text { with natural gas condensate added }\{20-30 \%\}) \text {, synbit } \\
\text { (synthetic bitumen }\{50 \%\} \text { with synthetic crude oil compounds } \\
\text { added }\{50 \%\} \text { ), and dilsynbit (a blend of the two common forms). } \\
\text { The primary volatile organic compounds of each product are } \\
\text { benzene, toluene, ethylbenzene, and xylene (BTEX) with ranges } \\
\text { of } 0.8-1.2 \% \text { in dilbit and } 0.4-1.1 \% \text { in synbit by volume and } \\
\text { approximately } 21 \% \text { more BTEX in dilbit than synbit on average. } \\
\text { The densities of both dilbit (945 kg/m }{ }^{3} \text { ) and synbit are less than } \\
\text { freshwater and will likely float initially. However, as "light ends" } \\
\text { (volatiles) and BTEX evaporate the heavier bitumen fraction } \\
\text { remains and has been shown to form droplets which disperse in } \\
\text { the water column in controlled, sediment-free lab tests in } 15^{\circ} \mathrm{C} \\
\text { water and after } 11 \text { days of UV exposure. Another study introduced } \\
\text { suspended particles - including kaolin, diatomaceous earth, and } \\
\text { sand - and found that while sand did not bind with the dilbit, the } \\
\text { kaolin and diatomaceous earth did, leading to droplets forming and } \\
\text { an increase in density by four orders of magnitude. These droplets } \\
\text { sank to the bottom of the water column. Similar effects were also } \\
\text { observed in the Enbridge Line } 6 \mathrm{~B} \text { dilbit spill into the Kalamazoo } \\
\text { River in } 2010 \text { where as much as } 10-20 \% \text { of oil mixed with } \\
\text { sediment immediately and } 20-30 \% \text { of the oil was still bound to the } \\
\text { sediment after } 3 \text { years. There have not been any studies on the fate } \\
\text { of synbit or dilsybit in freshwater systems. Though this paper did } \\
\text { not provide models it did provide valuable insights into the fate } \\
\text { and transport of Alberta tar sands oil products in freshwater. }\end{array}$ \\
\hline $\begin{array}{l}\text { Engineering ToolBox } \\
\text { (2003) }\end{array}$ & $\begin{array}{l}\text { Fuel type and density }(\rho) \text { range at } 15^{\circ} \mathrm{C} \text { : } \\
\text { - Diesel }(1 \mathrm{D}, 2 \mathrm{D}, \& 4 \mathrm{D})-875-959 \mathrm{~kg} / \mathrm{m}^{3} \\
\text { - } \text { Gasoline }-715-780 \mathrm{~kg} / \mathrm{m}^{3}\end{array}$ \\
\hline
\end{tabular}




\begin{tabular}{|c|c|}
\hline & $\begin{array}{ll}\text { - } & \text { Heavy fuel oil - 800-1010 kg/m } \\
\text { - } & \text { Jet fuel (Jet A \& Jet A-1) - 775-840 kg/m } \\
\text { - } & \text { Gas oil }-829-900 \mathrm{~kg} / \mathrm{m}^{3} \\
\end{array}$ \\
\hline Hayter et al. (2015) & 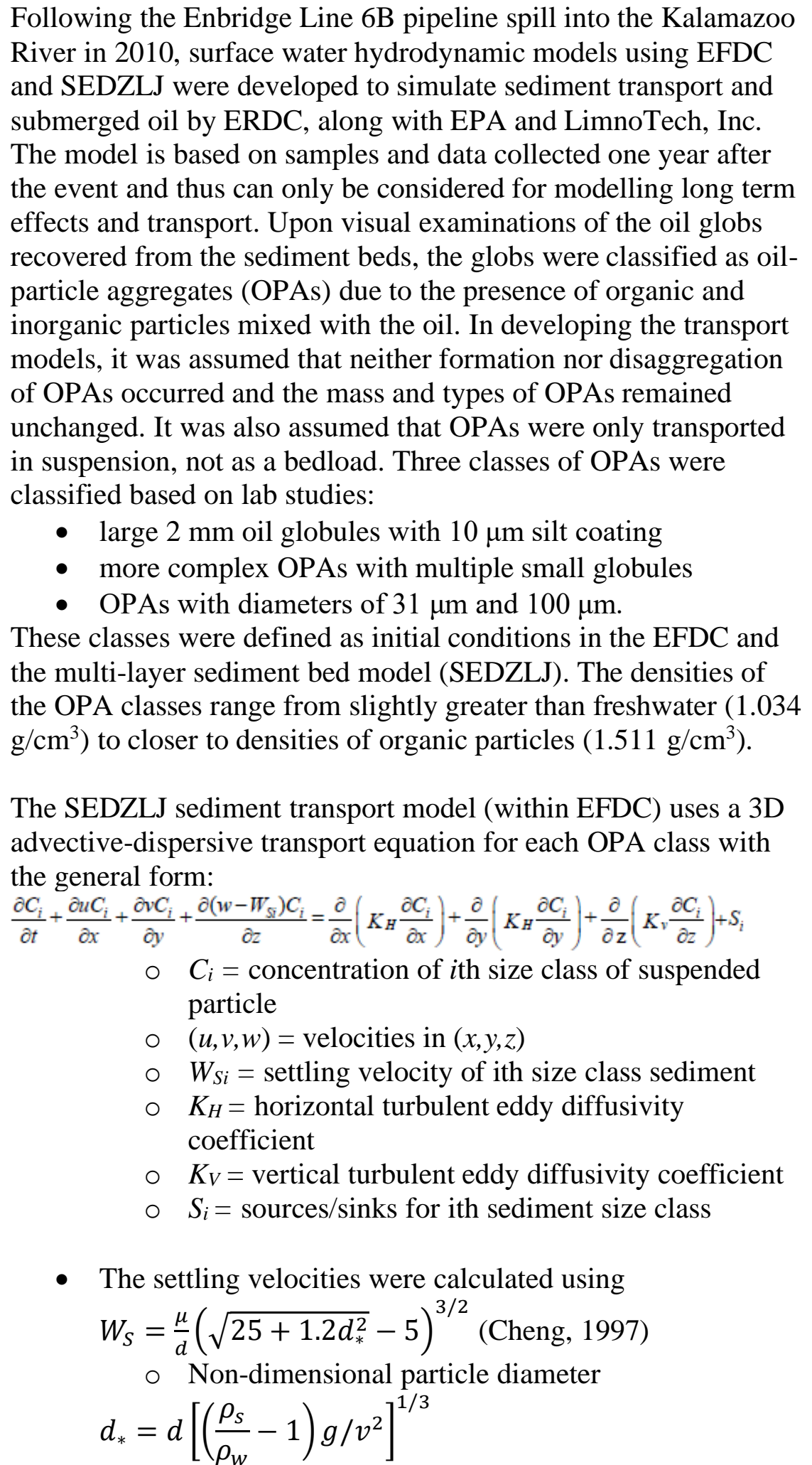 \\
\hline
\end{tabular}




\begin{tabular}{|c|c|}
\hline & $\begin{array}{ll}\circ & \mu=\text { dynamic viscosity of water } \\
\circ & d=\text { particle diameter } \\
\circ & \rho_{s}=\text { sediment particle density } \\
\circ & \rho_{w}=\text { density of water } \\
\circ & g=\text { acceleration due to gravity } \\
\circ & v=\text { kinematic fluid viscosity }\end{array}$ \\
\hline Hibbs et al. (1999) & 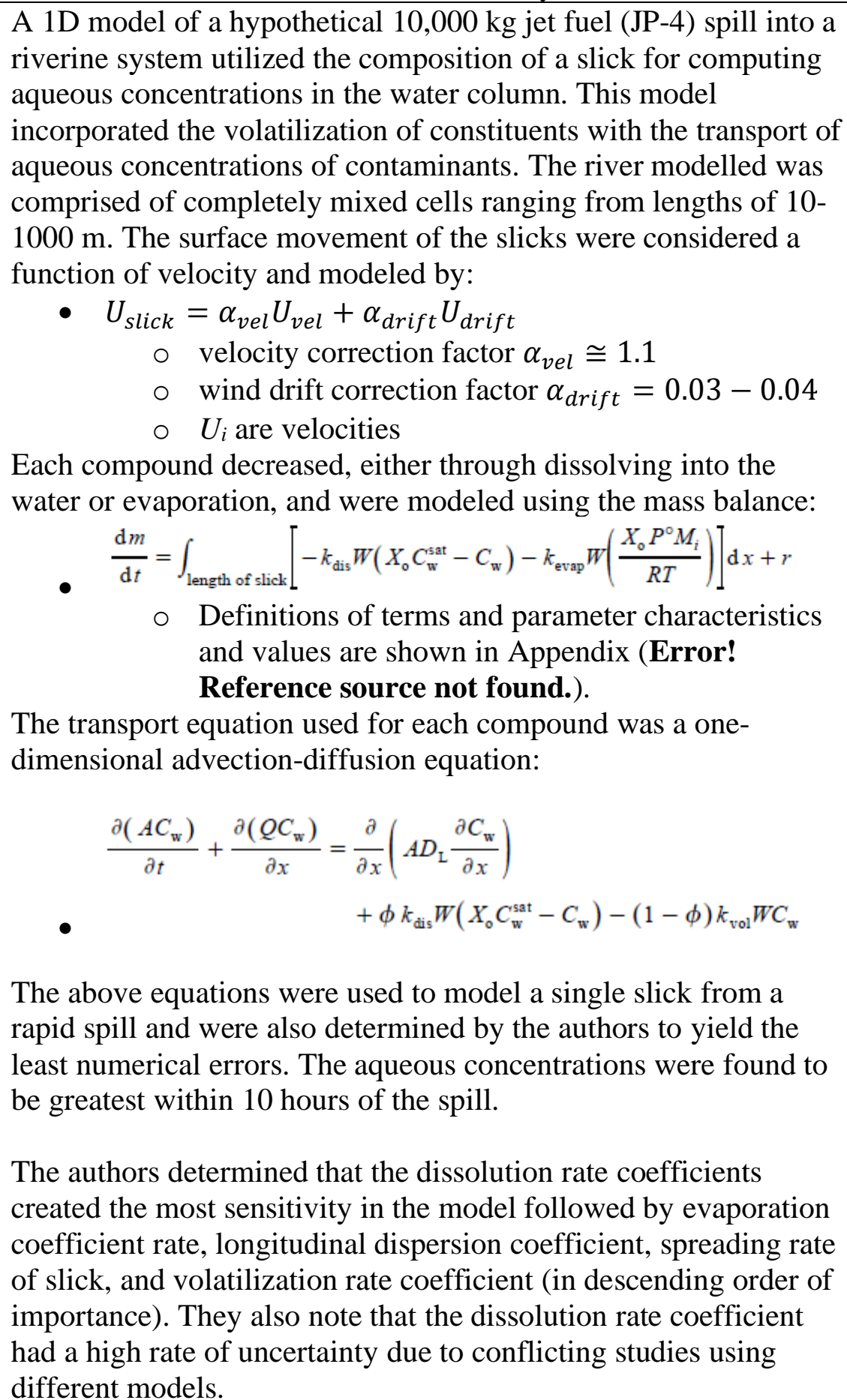 \\
\hline
\end{tabular}




\begin{tabular}{|c|c|c|c|}
\hline Njobuenwu et al. (2008) & $\begin{array}{l}\text { Benzene, toluen } \\
\text { major constitue } \\
\text { and mobile com } \\
\text { products when a } \\
\text { percent weight i } \\
\text { Table 3: Composition } \\
\text { 1995) }\end{array}$ & $\begin{array}{l}\text { nyl benzene, and xy } \\
\text { fresh gasoline. BT } \\
\text { nts in most crude o } \\
\text { to freshwater. The } \\
\text { sh gasoline in the ta } \\
\text { EX in fresh gasoline and }\end{array}$ & $\begin{array}{l}\text { ne (BTEX) are four } \\
X \text { are the most soluble } \\
\text { and refined petroleum } \\
\text { are represented by } \\
\text { le below: } \\
\text { e observation (Wiedemeir et al., }\end{array}$ \\
\hline & Composition & $\begin{array}{l}\% \text { Weight in fresh } \\
\text { gasoline }\end{array}$ & $\begin{array}{l}\text { Average \% weight } \\
\text { in } 3 \text { site samples }\end{array}$ \\
\hline & Benzene & $0.34-5.62$ & 0.87 \\
\hline & Toluene & $1.32-21.0$ & 3.2 \\
\hline & Ethyl benzene & $0.36-3.53$ & 1.1 \\
\hline & Xylene & $2.10-18.20$ & 2.8 \\
\hline & $\begin{array}{r}\text { The model deve } \\
\text { assumed to be a } \\
\text { and advection w } \\
\text { 1980). } \\
\text { - The diss } \\
\text { (Coulsor } \\
\text { dissoluti } \\
\text { The slicl } \\
\text { O L } \\
\text { p } \\
\text { L L } \\
0 \\
\text { A } \\
\text { The cont } \\
\text { Monaste } \\
\text { contamir } \\
\text { with a ha } \\
\text { The model resul } \\
\text { about 2.6, nearly } \\
\text { varying proporti } \\
\text { corresponding f } \\
\text { were determinec } \\
\text { Benzene } \\
\text { Toluene }\end{array}$ & 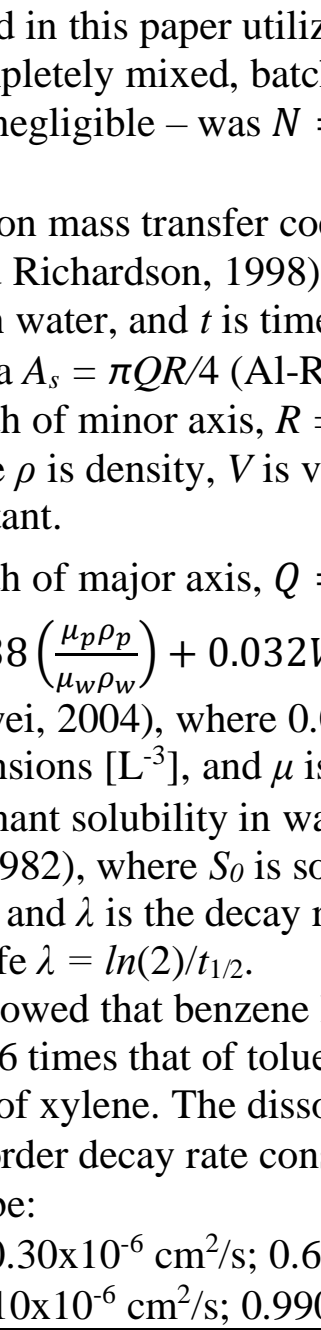 & $\begin{array}{l}\text { d the dissolution rate - } \\
\text { reactor where dilution } \\
K A_{s} S \text { (Cohen et al., } \\
\text { ficient } K=(D / \pi t)^{1 / 2} \\
D \text { is molecular } \\
\text { beh et al., } 1989) \text {. } \\
1.7\left(\rho_{w}-\rho_{p}\right)^{1 / 3} V_{p}{ }^{1 / 3} t^{1 / 4} \\
\text { ume, } w \text { is water, and } p \text { is } \\
{[10.111-} \\
t^{0.87}(\mathrm{Njobuenwu} \text { and } \\
32 \text { is constant with } \\
\text { viscosity. } \\
\text { er } S=S_{0} \lambda e^{t} \text { (Huang and } \\
\text { bility for fresh } \\
\text { te (first order of BTEX) } \\
\text { ad a dissolution rate of } \\
\text { e, ethylbenzene, and } \\
\text { ution rate, } K, \text { and } \\
\text { ants, } \lambda, \text { at } 25^{\circ} \mathrm{C} \text { in water } \\
31 \text { year }{ }^{-1} \\
\text { year }{ }^{-1}\end{array}$ \\
\hline
\end{tabular}




\begin{tabular}{|c|c|}
\hline & $\begin{array}{l}\text { - } \text { Ethylbenzene }-8.23 \times 10^{-6} \mathrm{~cm}^{2} / \mathrm{s} ; 0.5781 \text { year }^{-1} \\
\text { - Xylene }-8.23 \times 10^{-6} \mathrm{~cm}^{2} / \mathrm{s} ; 0.5781 \text { year }^{-1}\end{array}$ \\
\hline OSSPAC (2019) & $\begin{array}{l}\text { This report gives a high-level overview of the CEI Hub mitigation } \\
\text { strategies. It contains secondary source (attributed to Schick, T. } \\
2015 \text { data for OPB with no reference) reported values of fuel } \\
\text { volumes and distribution by number of tanks. Volumes (gal) were: } \\
\text { - } 118.2 \mathrm{M} \text { (gasoline) } \\
\text { - } 59.4 \mathrm{M} \text { (diesel) } \\
\text { - } 53.8 \mathrm{M} \text { (other petroleum, including Alberta bitumen } \\
\text { [confirmed by Dr. Dusicka by email } 2 \text { Feb 2021]) } \\
\text { - } 17.9 \mathrm{M} \text { (jet fuel) } \\
\text { - } 24.3 \mathrm{M} \text { (asphalt) } \\
\text { - } 14.9 \mathrm{M} \text { (not used) } \\
\text { More recent data on tank contents is unavailable. }\end{array}$ \\
\hline $\begin{array}{l}\text { Trusek-Holwnia, A. and } \\
\text { Noworyta, A. (2015) }\end{array}$ & $\begin{array}{l}\text { The average percent weight of BTEX in petrol (gasoline) is } 18 \% \text {. } \\
\text { The average percent of the individual volatile constituents are as } \\
\text { follows: } \\
\text { - Benzene }-1.98 \% \\
\text { - Toluene }-4.68 \% \\
\text { - Ethylbenzene }-1.98 \% \\
\text { - Xylene (total) }-9.36 \% \\
\circ \text { o-xylene }-2.16 \% \\
\circ \text { m-xylene }-5.58 \% \\
\circ \text { p-xylene }-1.62 \%\end{array}$ \\
\hline
\end{tabular}

\subsection{Literature review summary}

Liquid fuel or oil spills into riverine systems have complex behavior and vary greatly depending on fuel type and river conditions (e.g., flow rate, seasonal variability, dams, and turbidity).

Similarly, previously modeled results varied greatly depending on the model and its sensitivity to different parameters (Hibbs et al., 1999). There is also very little experimental data of oil spills in freshwater systems as oil companies are not required to perform such experiments (Dew et al., 2015). Thus, most data were historically collected in the field when an actual spill occurred. Though these data provide important information about oil-freshwater interaction (e.g., fate and transport), they are also limited by how quickly field testing begins after a spill, number of points sampled along the flow path, and long-term sampling (Clark et al. 1990). Sediment transport models have been developed to predict long-term oil-sediment interactions and oil-particle aggregate formations and transport. However, these do not provide insight into oil-sediment interaction immediately following a spill (Hayter et al. 2015).

Liquid fuels are typically less dense than water and thus float at the surface when a spill occurs unless dispersed through the water column by turbulent eddies (Engineering ToolBox, 2003; Dew et al. 2015; Shen and Yapa, 1988). A fraction of the fuels are volatile organic compounds (VOCs) which diminish the mass of the fuel slick within hours through evaporation into the atmosphere and dissolution into the water column (Figure 3). For the heavier oils, the 
evaporation and dissolution of VOCs can increase the oil density to just greater than water causing a portion of the slick to sink below the surface. However, this can take over 10 days to occur and is greatly affected by weathering and suspended solids interactions (Dew et al., 2015). Benzene, toluene, ethylbenzene, and xylene (BTEX) are the primary VOCs in gasoline and tar sands oil (Njobuenwu et al., 2004; Trusek-Holwnia and Noworyta, 2015; and Dew et al., 2015). Benzenes, tetralin, napthenes, methylcyclohexane, and aliphatics are the VOCs found in JP-4 jet fuel (Hibbs et al., 1999). The VOC fraction for USLC diesel, a common type used in the US, is approximately 10\% (Chin and Batterman, 2012).

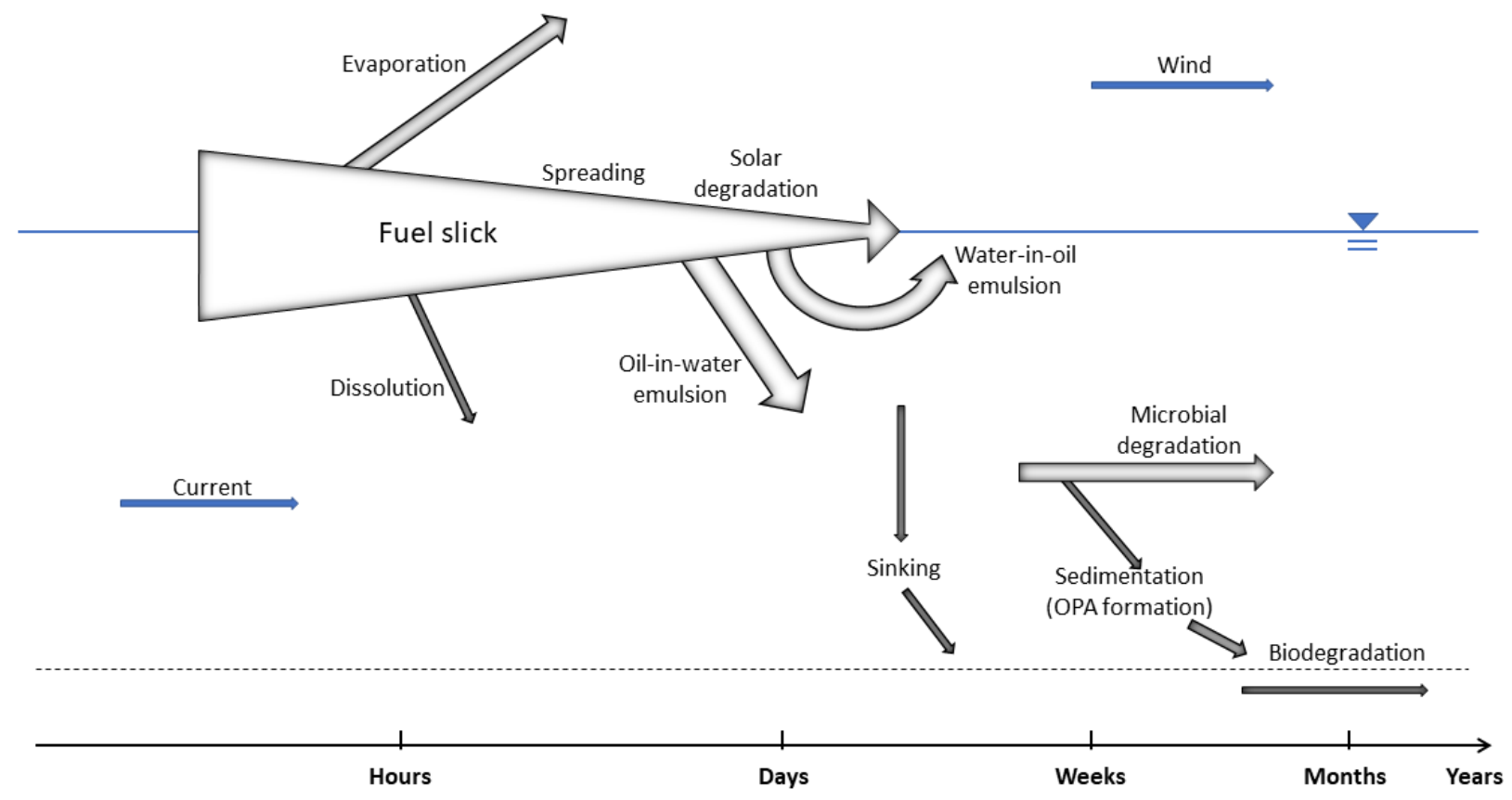

Figure 3: Liquid fuel slick transformation in rivers (modified from Shen and Yapa, 1988).

\section{CE-QUAL-W2 model}

\section{1. $C E-Q U A L-W 2$ model inputs from literature}

The models reviewed for this report varied from 1D, 2D, and 3D hydrodynamic and sediment transport models based on governing equations, assumptions, and parameters that frequently differ from those required for the CE-QUAL-W2 model. The parameters selected from the literature were based on the inputs required for the volatile generic constituent equation for the CE-QUAL-W2 model:

$$
\begin{gathered}
S_{v o l}=\frac{A_{\text {sur }}}{V_{\text {cell }}} K_{L g}\left(\Phi_{s g}-\Phi_{g}\right)=\frac{1}{h_{K T}} K_{L g}\left(\Phi_{s g}-\Phi_{g}\right) \\
\Rightarrow K_{L g}=K_{L 02}\left(\frac{M W_{02}}{M W}\right)^{0.25}=K_{L 02} \times C G K L F
\end{gathered}
$$


where:

$\mathrm{K}_{\mathrm{Lg}}=$ the surface gas transfer coefficient for a generic constituent $(\mathrm{m} / \mathrm{s})$

$\mathrm{A}_{\text {sur }}=$ the surface area of the surface layer computational cell $\left(\mathrm{m}^{2}\right)$

$\mathrm{V}_{\text {cell }}=$ the volume of the surface layer computational cell $\left(\mathrm{m}^{3}\right)$

$\mathrm{h}_{\mathrm{KT}}=$ depth of the surface layer $(\mathrm{K}=\mathrm{KT})$ computational cell $(\mathrm{m})$

$\phi_{\mathrm{g}}=$ the liquid phase generic constituent concentration $\left(\mathrm{g} / \mathrm{m}^{3}\right)$

$\phi_{\mathrm{sg}}=$ the hypothetical saturation liquid phase if in equilibrium with the gas concentration $\left(\mathrm{g} / \mathrm{m}^{3}\right)$ based on the gas phase concentration and the Henry's Law constant (Wells, 2019a).

The gas transfer coefficients (CGKLF) for each constituent were calculated from their molecular weights. The first order decay rates were only found for BTEX constituents ([Insert table citation]). Fuel types stored at the CEI Hub were only reported as volumes and generically (e.g, gasoline, jet fuel, etc.) opposed to specific fuel type (OSSPAC, 2019). Thus, densities were averaged based on the ranges provided (Engineering ToolBox, 2003 and Dew et al, 2015).

\subsection{Simplifying assumptions for CE-QUAL-W2 model inputs}

To simplify the input parameters for the CE-QUAL-W2 model, the following assumptions were made:

- All fuels stored at the CEI Hub were generalized into four generic types: gasoline, diesel, other petroleum (dilbit or Alberta tar sands oil), and jet fuel (JP-4) (Table 3).

- The 1st-order decay rates (CG1DK) and gas transfer coefficients (CGKLF) were averaged and applied to the volatile fraction (VOC) (Table 4).

- Each fuel was separated into its volatile (VOC) and non-volatile (NON-VOC) constituent mass fractions (\%) and summed (Table 5).

- The non-volatile fraction was assumed conservative.

- The Arrhenius rate multipliers, 0-order decay rates, settling rates, photodegradation parameters, and gas transfer saturations for Generic Constituents in the model were neglected.

- $100 \%$ of liquid fuel stored at the CEI Hub were spilled into the Willamette River to model the worst-case scenario.

- Modeled spills occurred over 1 hour, 1 day, and 1 week time periods to account for possible containment berms and containment failures.

- Spill discharge rates assumed constant over spill duration.

- Temperature of fuel assumed as a constant $20^{\circ} \mathrm{C}$. 
Table 4: Volatile constituents and corresponding properties

\begin{tabular}{l|c|c|c|}
\hline $\begin{array}{l}\text { Volatile } \\
\text { constituents }\end{array}$ & $\begin{array}{l}\text { Molecular } \\
\text { weight } \\
(\mathrm{g} / \mathrm{mol})\end{array}$ & $\begin{array}{l}\text { Gas transfer } \\
\text { factor }^{\mathrm{b}} \\
\text { [CGKLF] (-) }\end{array}$ & $\begin{array}{l}\text { 1st-order decay } \\
\text { constant }^{\mathrm{c}} \\
\text { [CG1DK] }\left(\text { day }^{-1}\right)\end{array}$ \\
\hline \hline Benzene & 78 & 0.800 & 0.00190 \\
\hline Toluene & 92 & 0.768 & 0.00271 \\
\hline Ethyl-benzene & 106 & 0.741 & 0.00158 \\
\hline Xylene & 106 & 0.741 & 0.00158 \\
\hline $\begin{array}{l}\text { n-Butyl- } \\
\text { benzene }\end{array}$ & 134.2 & 0.699 & - \\
\hline Tetralin & 132.2 & 0.701 & - \\
\hline $\begin{array}{l}\text { 1-Methyl- } \\
\text { napthalene }\end{array}$ & 142.2 & 0.689 & - \\
\hline $\begin{array}{l}\text { 1,4,-Dimethyl- } \\
\text { naphthalene }\end{array}$ & 156.2 & 0.673 & - \\
\hline $\begin{array}{l}\text { Methylcyclo- } \\
\text { hexane }\end{array}$ & 98.2 & 0.756 & - \\
\hline Aliphatics & 145.7 & 0.685 & - \\
\hline Average & & 0.725 & 0.00194 \\
\hline
\end{tabular}

${ }^{a}$ Hibbs et al. (1999)

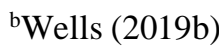

${ }^{\mathrm{C} N j o b u e n w u ~ e t ~ a l . ~(2005) ~}$

\subsection{Model set up and initialization}

The CE-QUAL-W2 calibration model years were compared against USGS average annual flow rates for the Willamette River (Table 1). Models for 1997 and 1994 were selected for highest and lowest annual discharge rates, respectively, of the years modeled. The spills were chosen to occur on 2 May (Julian day 122), 1997 and 15 July (Julian day 197), 1994 - the highest (1209 $\left.\mathrm{m}^{3} / \mathrm{s}\right)$ and lowest $\left(182 \mathrm{~m}^{3} / \mathrm{s}\right)$ discharge days of those years - to capture the possible extreme scenarios of a spill. Three spill scenarios were created for each of the years for intervals of 1 hour, 1 day, and 1 week. A tributary for the spill was added at segment 93 (Figure 4) at the approximate midpoint of the CEI Hub on the Lower Willamette River. The corresponding concentration $(\mathrm{C})$, discharge rate $(\mathrm{Q})$, and temperature $(\mathrm{T})$ files were added to the file directories and control files. C and Q were calculated from the fuel mass-fraction (Table 5) using $m=$ 
$C Q \Delta t$, where $m$ is mass fraction in $\mathrm{kg}$, and $\Delta t$ is time interval for spill (1-hour, 1-day, and 1week) in seconds.

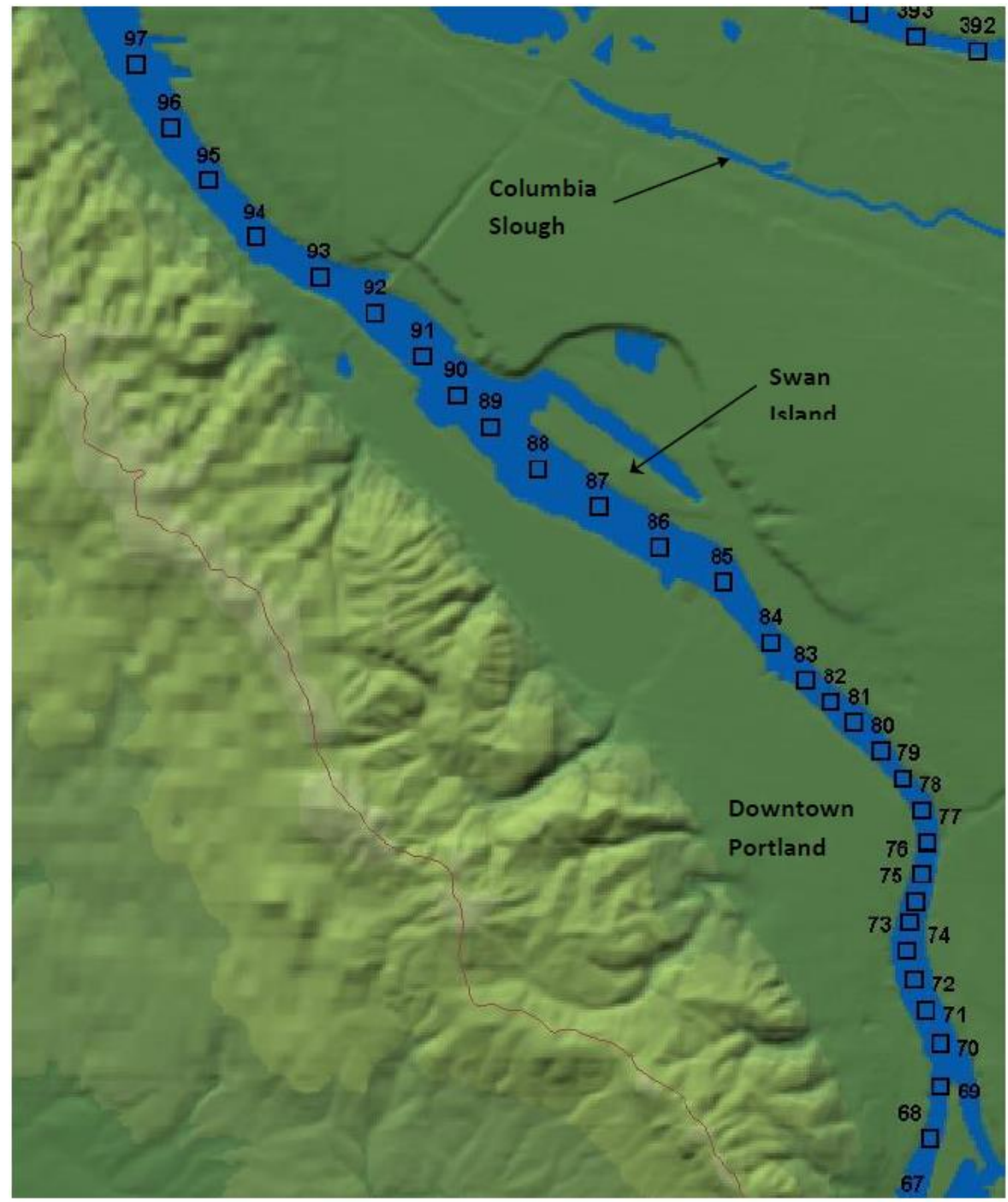

Figure 4: Model segment numbers in the Lower Willamette River near the CEI Hub and downtown Portland (Berger et al., 2001).

The spill flow rates, assumed constant for each of the modeled durations, were calculated as $274.39 \mathrm{~m}^{3} / \mathrm{s}$ for the 1-hour spill, $11.43 \mathrm{~m}^{3} / \mathrm{s}$ for the 1 -day spill, and $1.63 \mathrm{~m}^{3} / \mathrm{s}$ for the 1 -week spill duration. Constant fuel spill concentrations were calculated for each constituent fraction based 
on the total mass-fraction and total fuel volume as $743,071 \mathrm{~g} / \mathrm{m}^{3}$ for the conservative fraction, and $92,368 \mathrm{~g} / \mathrm{m}^{3}$ for the volatile fraction.

Table 5: Simplified total volumes and masses of fuels at CEI Hub

\begin{tabular}{|c|c|c|c|c|c|c|c|}
\hline Fuel type & $\begin{array}{l}\text { Density }{ }^{\mathrm{a}} \\
\left(\mathrm{kg} / \mathrm{m}^{3}\right)\end{array}$ & $\begin{array}{l}\% \operatorname{VOC}^{c} \\
\text { (by wt.) }\end{array}$ & $\begin{array}{c}\text { Total volume }{ }^{d} \\
\left(\mathrm{~m}^{3}\right)\end{array}$ & $\begin{array}{c}\text { Total mass } \\
(\mathrm{kg})\end{array}$ & $\begin{array}{c}\text { VOC mass } \\
(\mathrm{kg})\end{array}$ & $\begin{array}{c}\text { Non-VOC mass } \\
(\mathrm{kg})\end{array}$ & 'Reference \\
\hline Gasoline & 748 & 18 & 447388 & 334422786 & 60196101 & 274226684 & Trusek-Holwnia and Noworvta (2015) \\
\hline Diesel & 917 & 10 & 224830 & 206168812 & 20616881 & 185551930 & Chin and Batterman (2012) \\
\hline Dilbit (tar sands) & $945^{b}$ & 1.2 & 216897 & 204967506 & 2459610 & 202507896 & Dew et al. (2015) \\
\hline Jet fuel (Jet A) & 808 & 10 & 98700 & 79700447 & 7970045 & 71730402 & assumed (data unavailable) \\
\hline Total & & & 987815 & 825259550 & 91242637 & 734016913 & \\
\hline
\end{tabular}

${ }^{\mathrm{a}}$ Engineering Toolbox (2003) (averaged)

${ }^{\mathrm{b}}$ Dew et al. (2015)

${ }^{\mathrm{O} O S S P A C}(2019)$

The generic constituent sections of the CE-QUAL-W2 control files were updated from version 4.1 to version 4.2 to include the additional parameters in the newer version. The "TRACER" and "EColi" generic constituents were changed to "NON-VOC" and "VOC," respectively, and the constituent concentration control sections updated to reflect the changes. The tracer and coliform (E. coli) columns in all tributary and branch concentration input files were zeroed out to ensure that the NON-VOC and VOC concentrations from the spill were the sole input parameters that the model read. An average 1st-order decay rate (CG1DK) of $0.00194 \mathrm{day}^{-1}$ and gas transfer factor (CGKLF) of 0.725 were applied to the VOC constituent. CG1DK and CGKLF were assumed to be zero (conservative) for the NON-VOC constituent.

\section{Model results}

Three scenarios - 1-hour, 1-day, and 1-week spill durations - for the liquid fuel spill CE-QUALW2 model years 1994 and 1997 were run for a total of six simulations. River velocities and flow rates in the longitudinal direction, and total surface concentrations of the fuel spills were analyzed at five locations: the Fremont Bridge upstream of the spill (segment 85) and the St. Johns Bridge immediately downstream of the spill (segment 94) in the Willamette River at Portland (Figure 4), as well as St. Helens (segment 276), Rainier (segment 322) and the Beaver Army Terminal (the model terminus; segment 356) in the Columbia River on the Oregon side (Berger et al. 2001).

\subsection{Velocity and flow rate plots}

The velocities and flow rates for a 10-day period, beginning when the spills occur, were compared at one location on each river: the Fremont Bridge in Portland on the Willamette River and at Rainier on the Columbia River.

\subsubsection{Willamette River}

The daily fluctuations in the velocity at the surface and flow rate in the Willamette River are shown in Figure 5 and Figure 6, respectively, analyzed at the Fremont Bridge, or segment 85 (see Figure 4), are due to tidal fluctuations. The Columbia River terminates at the Pacific Ocean which transmits tidal head fluctuations upstream to the Bonneville Dam. The Willamette River is a tributary of the Columbia River and is thus influenced by its tidal fluctuations. The velocity and flow rate decreases as the tidal energy is transmitted upstream from the confluence of the 
two rivers. Similarly, the velocity and flow rate increase as the transmitted tidal head ebbs. These fluctuations have a much greater amplitudes during low flow years, as opposed to high flow years where the amplitudes of the tidal fluctuations are relatively small, approaching a constant velocity. Because the flow rate is function of velocity and area, and they are each calculated at a single segment in the longitudinal direction, the flow rate (Figure 6) has a nearly identical pattern to the velocity at the surface (Figure 5). Additionally, negative velocity and flow rate values indicate flow is traveling in the upstream direction.

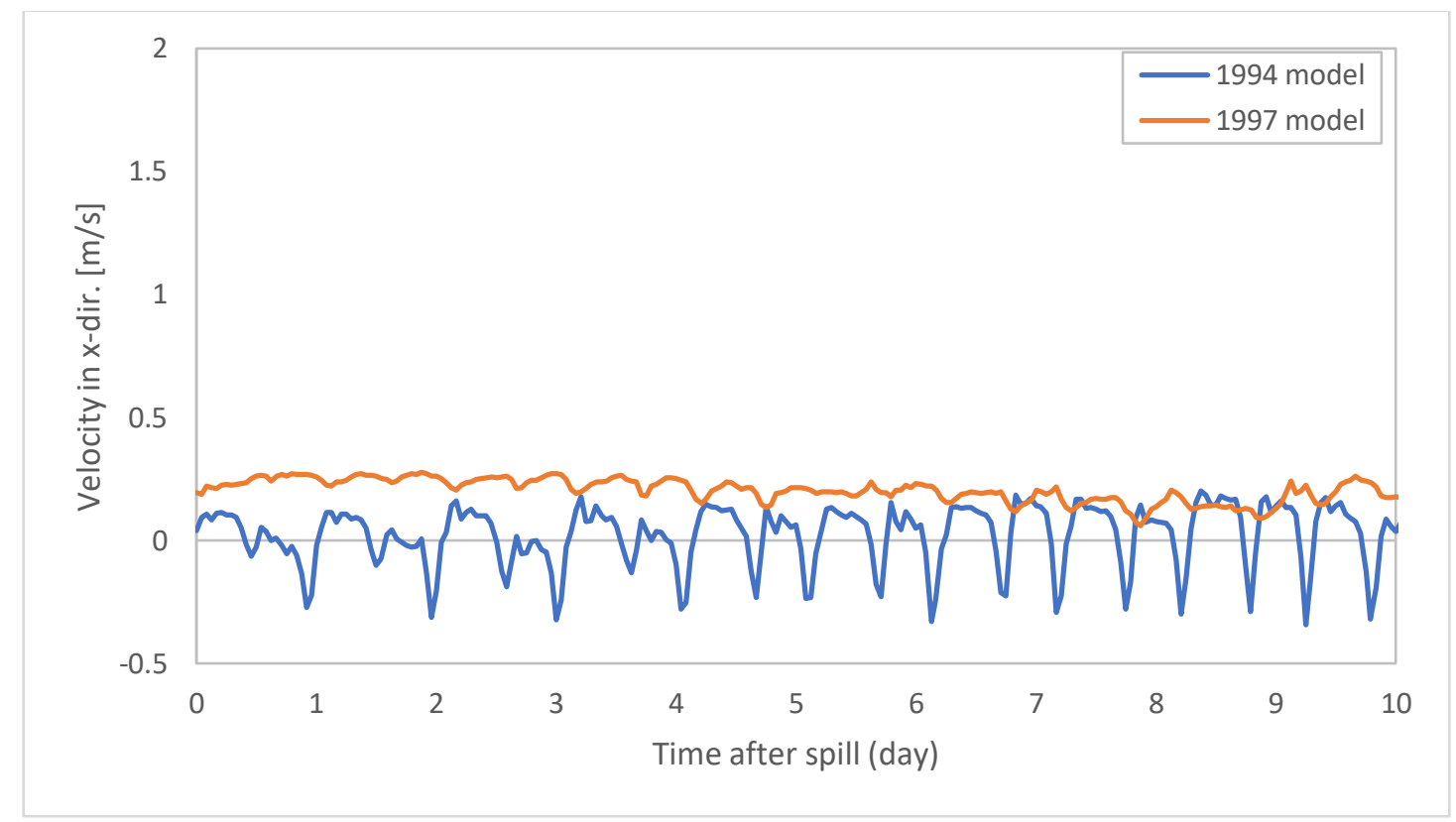

Figure 5: Surface velocity at the Fremont Bridge (seg. 85).

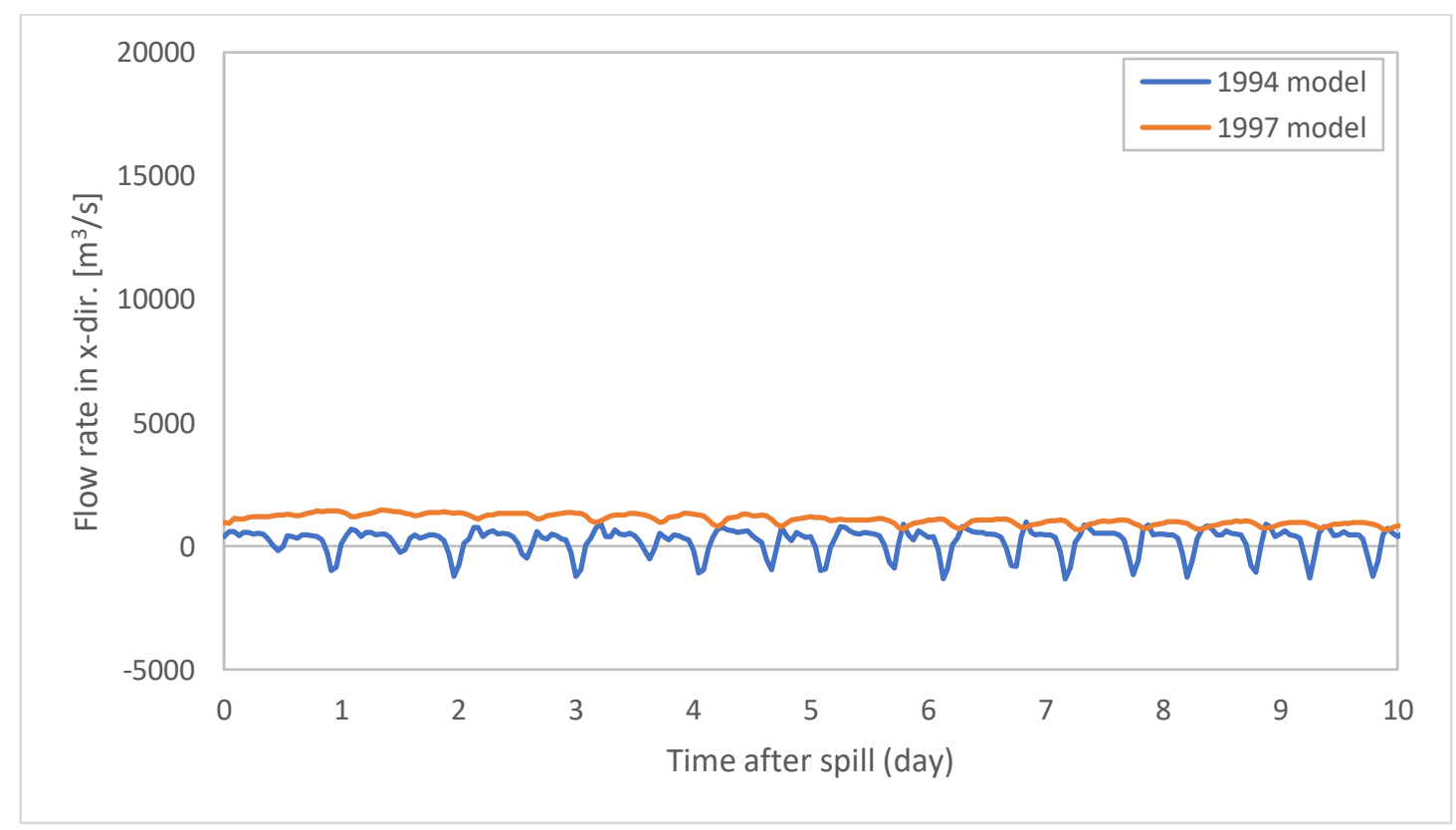

Figure 6: Flow rate at the Fremont Bridge (seg. 85). 


\subsubsection{Columbia River}

The fluctuations in the velocity at the surface and flow for the Columbia River (Figure 7 and Figure 8) are, as explained in section 4.4.1, due to tidal head at the Pacific Ocean boundary of the river. The flow rates, however, are approximately an order of magnitude greater than those in the Willamette River (Figure 6) and the velocities nearly five-times greater (Figure 5). Moreover, the fluctuations and rates are much more uniform for the Columbia River and are in the upstream longitudinal direction far less frequently and for shorter durations. The same initial pattern variations at the beginning of the 1997 model are visible, and more pronounced, as in the Willamette River model branch.

It should be noted that the unusual patterns at the beginning of the profiles from the 1997 model are likely errors due to closeness of the initialization date of the model (Julian date 121) and the spill start date (Julian date 122). The spill dates were selected of actual sensor data, as mentioned in section 3.3, which happened to occur immediately after the model initialization.

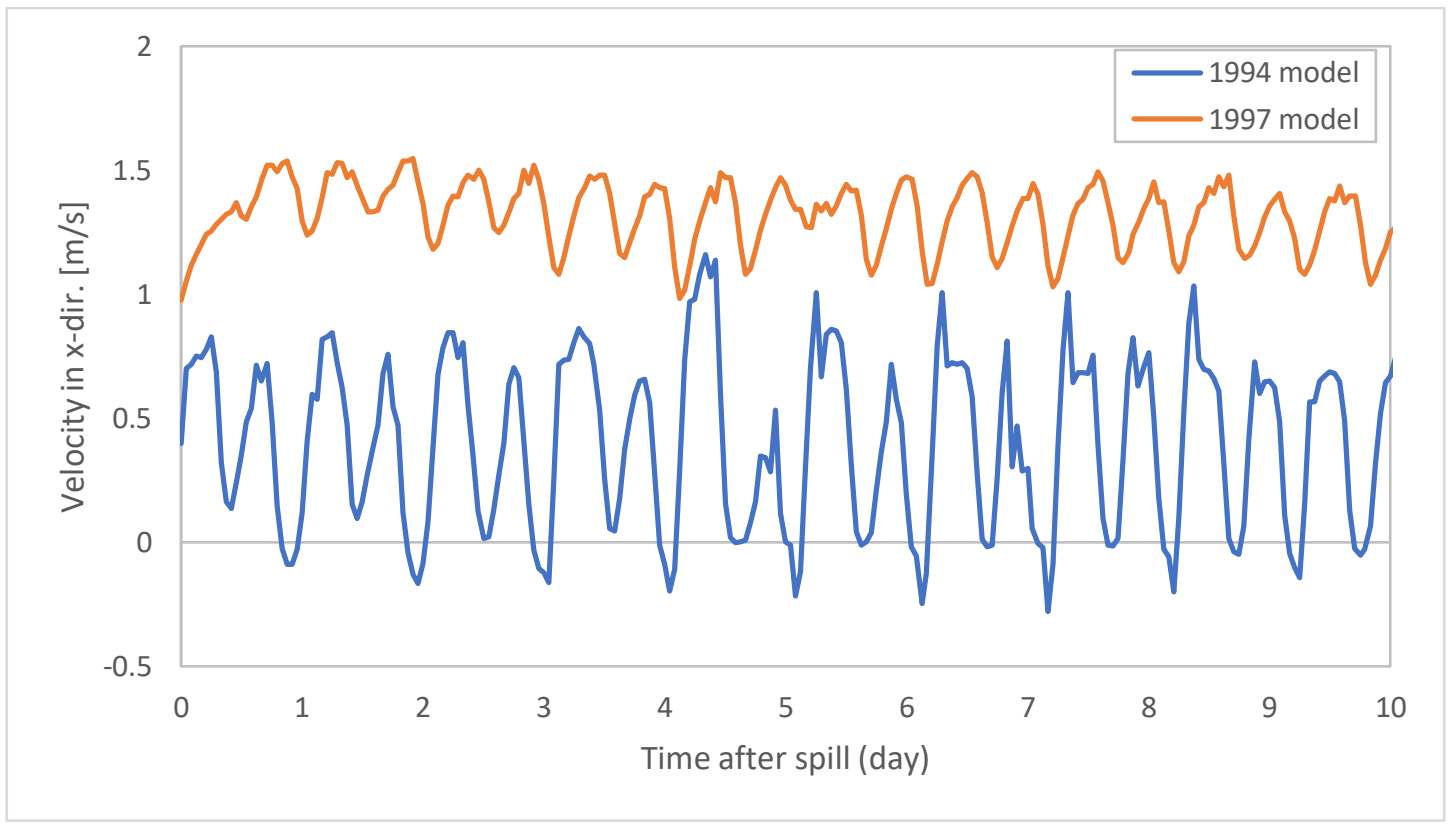

Figure 7: Surface velocity at Rainier, OR (seg. 322). 


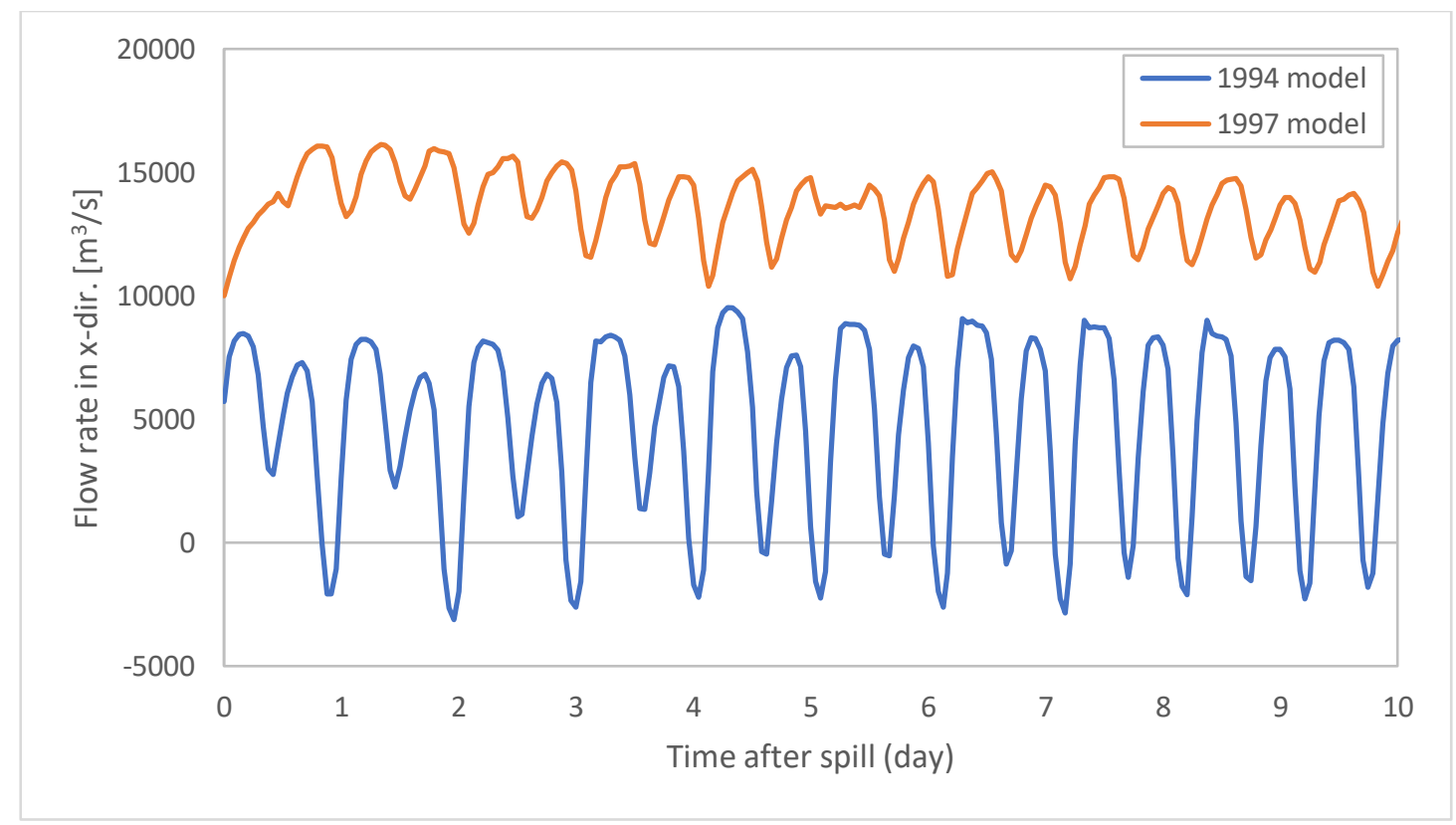

Figure 8: Flow rate at Rainier, OR (seg. 322).

\subsection{Total fuel spill concentrations at the water surface}

The conservative (nonvolatile) and volatile (VOC) fractions were summed using the principle of superposition to create plots of the total fuel spill concentrations at the surface. They were compared at each chosen location based on spill scenarios 1-hour, 1-day, and 1-week modeled.

\subsubsection{Fremont Bridge, Portland, OR (seg. 85)}

Model segment 85 is located upstream of the model spill tributary in the Willamette River approximately at the Fremont Bridge, Portland, OR.

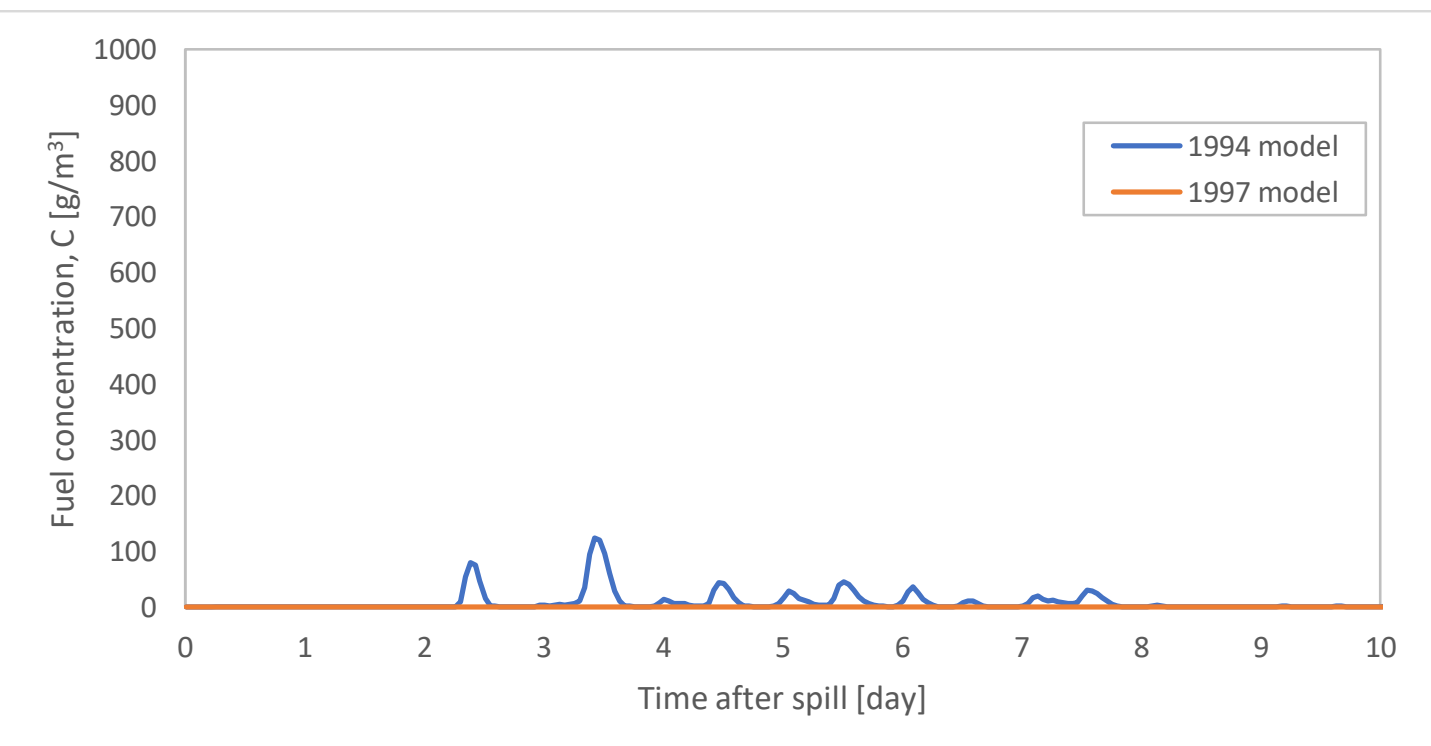

Figure 9: 1-hour spill duration at the Fremont Bridge (upstream; seg. 85) in the Willamette River. 


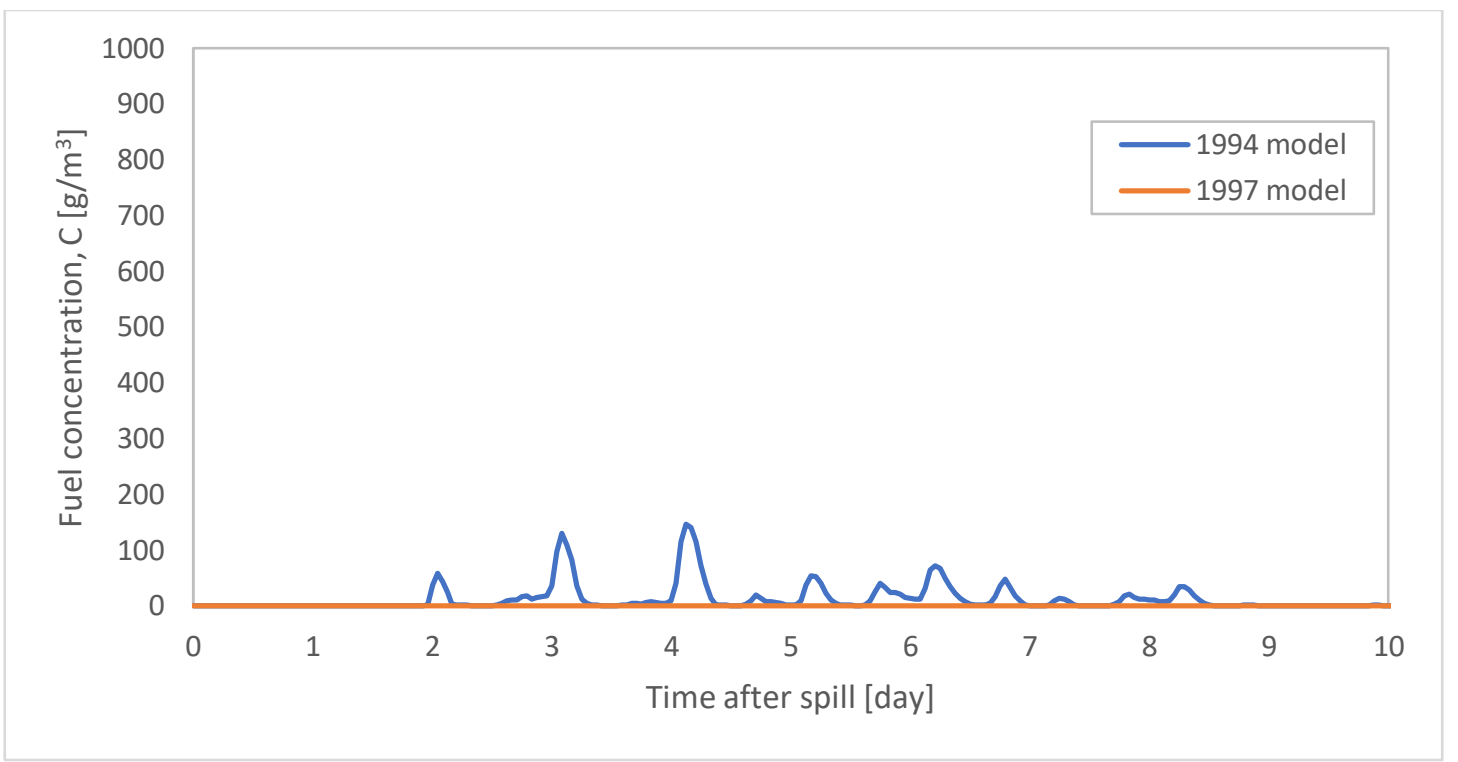

Figure 10: 1-day spill duration at the Fremont Bridge (upstream; seg. 85) in the Willamette River.

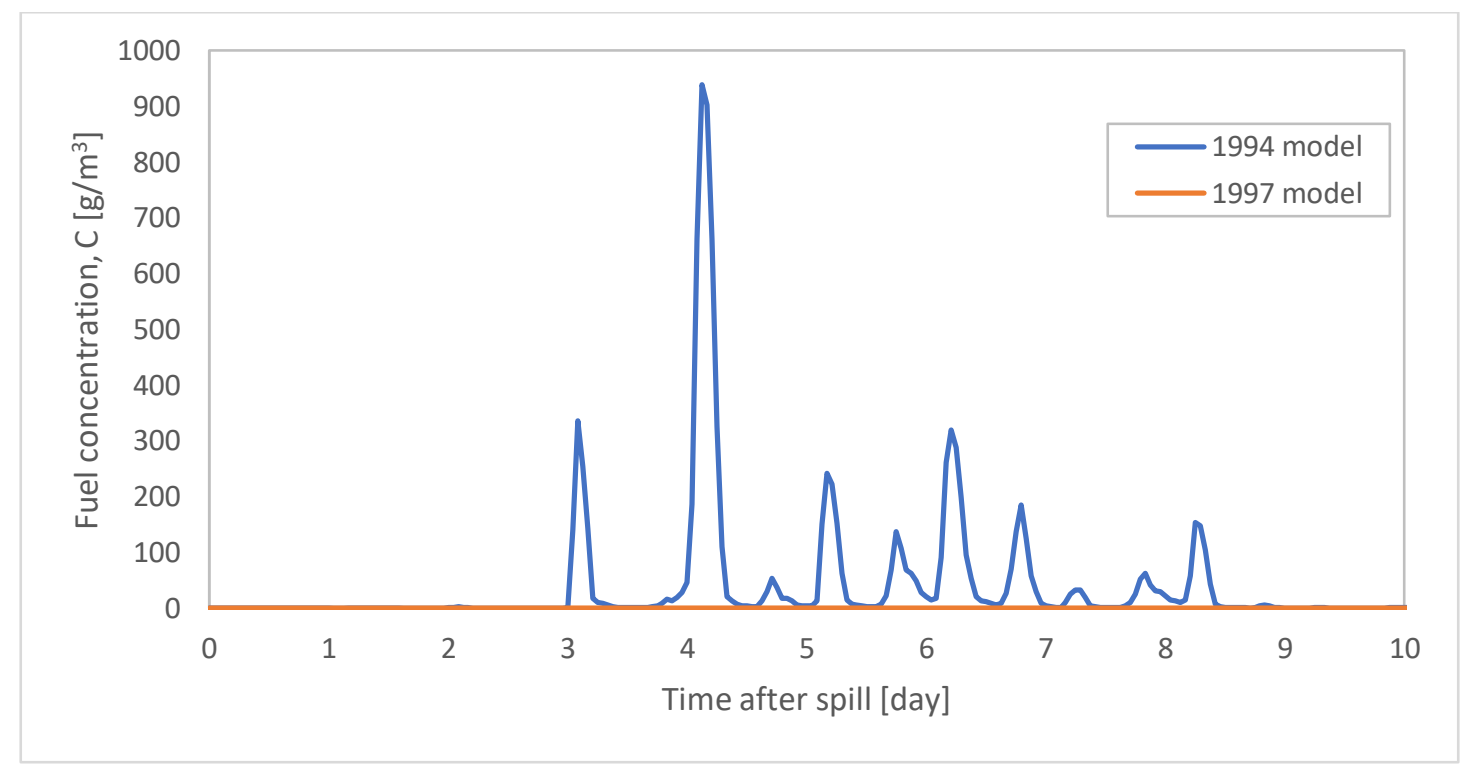

Figure 11: 1-week spill duration at the Fremont Bridge (upstream; seg. 85) in the Willamette River.

For all three spill scenarios, the plume did not travel upstream at all during high flow model year (1997). However, the plume traveled upstream during the low flow model year (1994), taking between two and three days to arrive and fluctuating for as long as seven days in the 1-day spill scenario. The maximum spill concentrations occurred between the third and fifth day after the spill and were $123 \mathrm{~g} / \mathrm{m}^{3}, 146 \mathrm{~g} / \mathrm{m}^{3}$, and $939 \mathrm{~g} / \mathrm{m}^{3}$ for the 1-hour (Figure 9), 1-day (Figure 10), and 1-week (Figure 11) spill durations, respectively. 


\subsubsection{St. Johns Bridge, Portland, OR (seg. 94)}

Model segment 94 is located immediately downstream of the model spill tributary (segment 93) in the Willamette River at the St. Johns Bridge, Portland, OR.

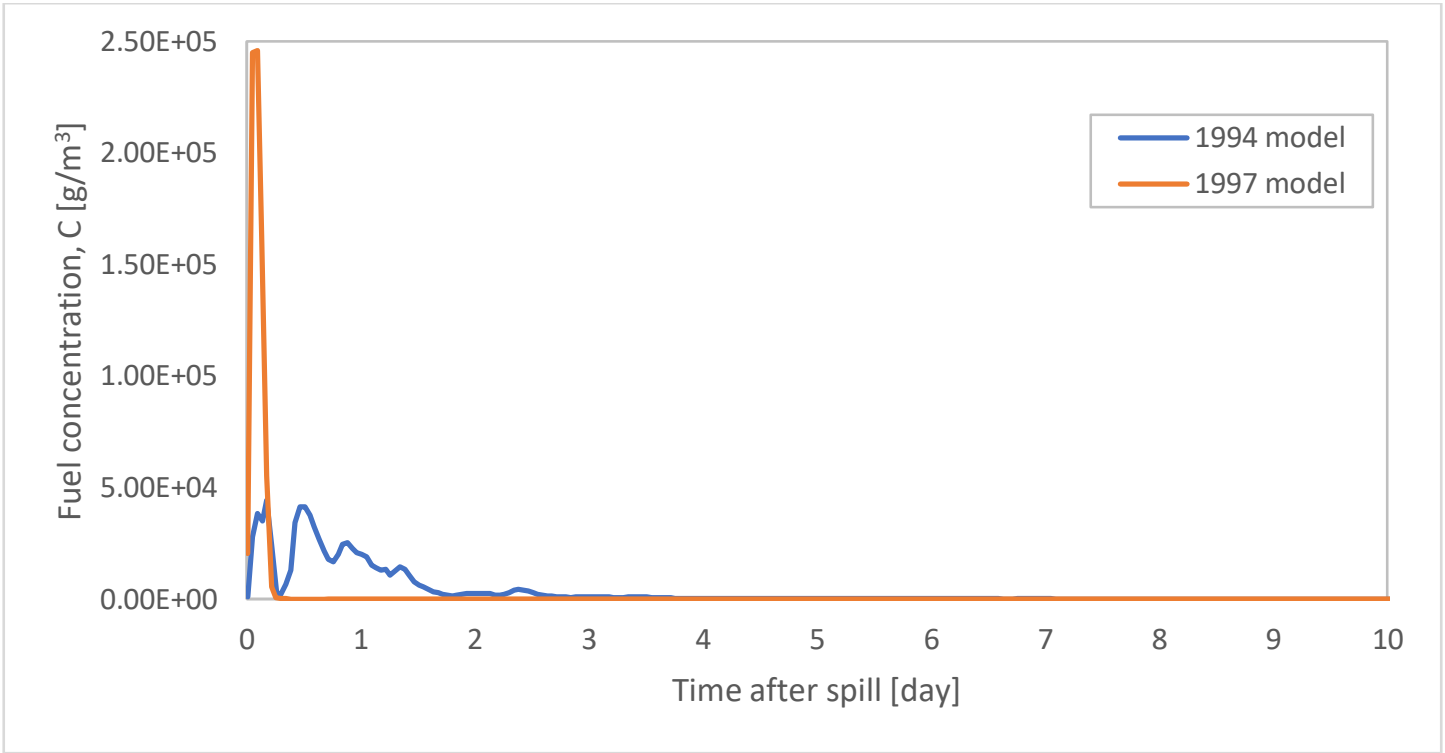

Figure 12: 1-hour spill duration at the St. Johns Bridge (immediately downstream; seg. 94) in the Willamette River.

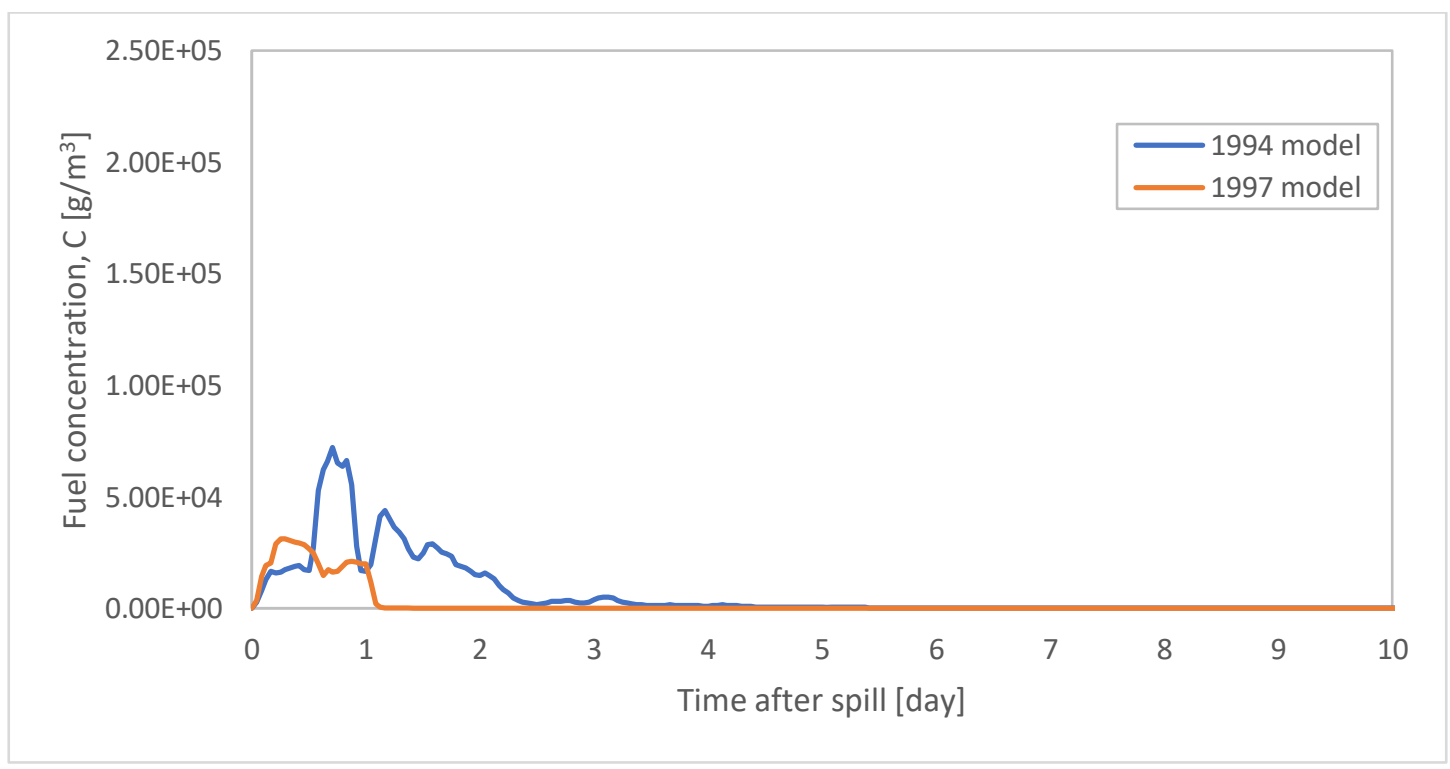

Figure 13: 1-day spill duration at the St. Johns Bridge (immediately downstream; seg. 94) in the Willamette River. 


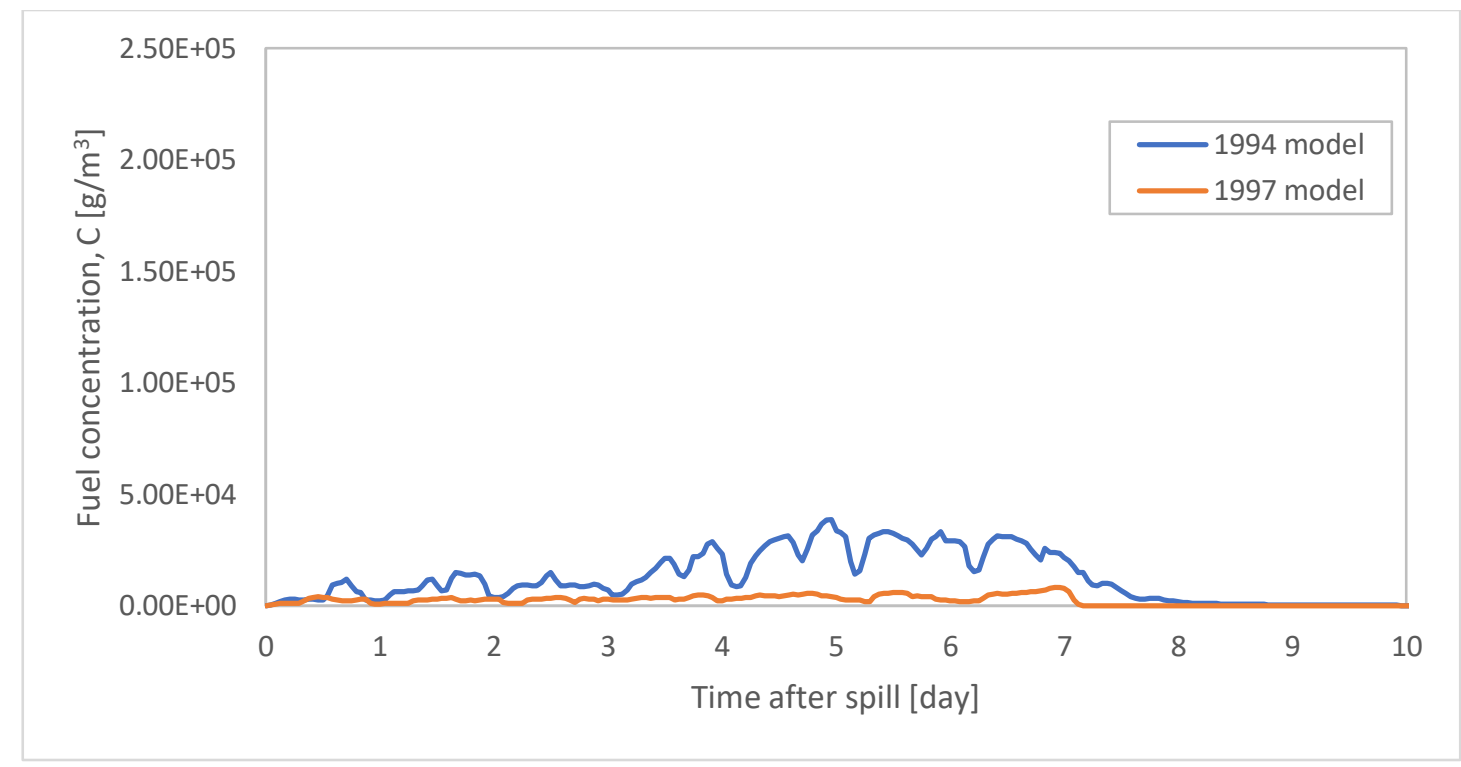

Figure 14: 1-week spill duration at the St. Johns Bridge (immediately downstream; seg. 94) in the Willamette River.

For the 1-hour spill duration (Figure 12), the high flow model year fuel concentration was a highly concentrated front that arrived and dissipated within a few hours, whereas the low flow model year had a much lower fuel concentration that gradually decreased over several days. Moreover, The tidal influence was apparent for the low flow year by the fluctuations in the fuel concentration level. The maximum concentrations for the high and low flow years were 246,000 $\mathrm{g} / \mathrm{m}^{3}$ and $44,200 \mathrm{~g} / \mathrm{m}^{3}$, respectively.

The high flow year fuel concentrations for the 1-day spill duration (Figure 13) were significantly less than the 1-hour spill, with a maximum of $31,100 \mathrm{~g} / \mathrm{m}^{3}$, and lasted for only the duration of the spill. The general behavior for the low flow model year, however, were nearly identical to the 1hour spill, but with a higher maximum concentration of $72,100 \mathrm{~g} / \mathrm{m}^{3}$ and a longer residence time by almost a day.

The high flow year fuel concentrations over the 1-week spill duration (Figure 14) had a maximum concentration of $8,240 \mathrm{~g} / \mathrm{m}^{3}$, nearly $1 / 30$ of the maximum concentration for a 1-hour spill. The maximum fuel concentration for the low flow year was $38,600 \mathrm{~g} / \mathrm{m}^{3}$, within the same order of magnitude as the other two scenarios. As with the 1-hour and 1-day scenarios, the concentration for the high flow year reduces to nearly zero almost immediately after the end of the spill, whereas the residence time for the low flow year lasted for more than a day after the end of the spill.

\subsubsection{St. Helens, OR (seg. 276)}

Model segment 276 is located just before the town of St. Helens, OR in the Columbia River.

The first segment analyzed in the Columbia River, the behaviors of the plumes for the high flow model year are very similar to those in the Willamette River for all scenarios, only shifted by approximately one day and a fraction of the concentration. The maximum concentration for the 
high flow year were $1,880 \mathrm{~g} / \mathrm{m}^{3}, 683 \mathrm{~g} / \mathrm{m}^{3}$, and $120 \mathrm{~g} / \mathrm{m}^{3}$ for the 1-hour (Figure 15), 1-day (Figure 16), and 1-week (Figure 17) spill duration scenarios, respectively.

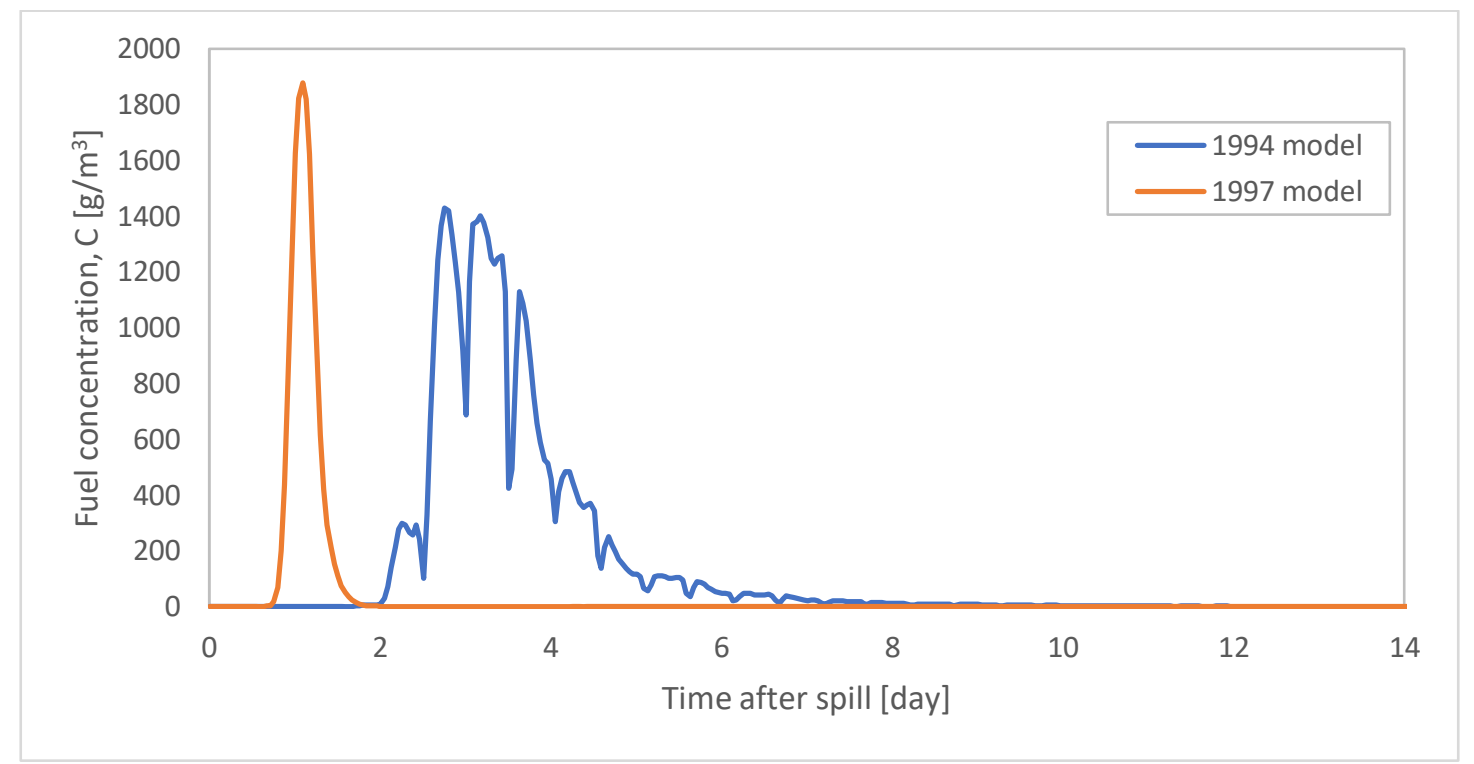

Figure 15: 1-hour spill duration at St. Helens, OR (seg. 276) in the Columbia River.

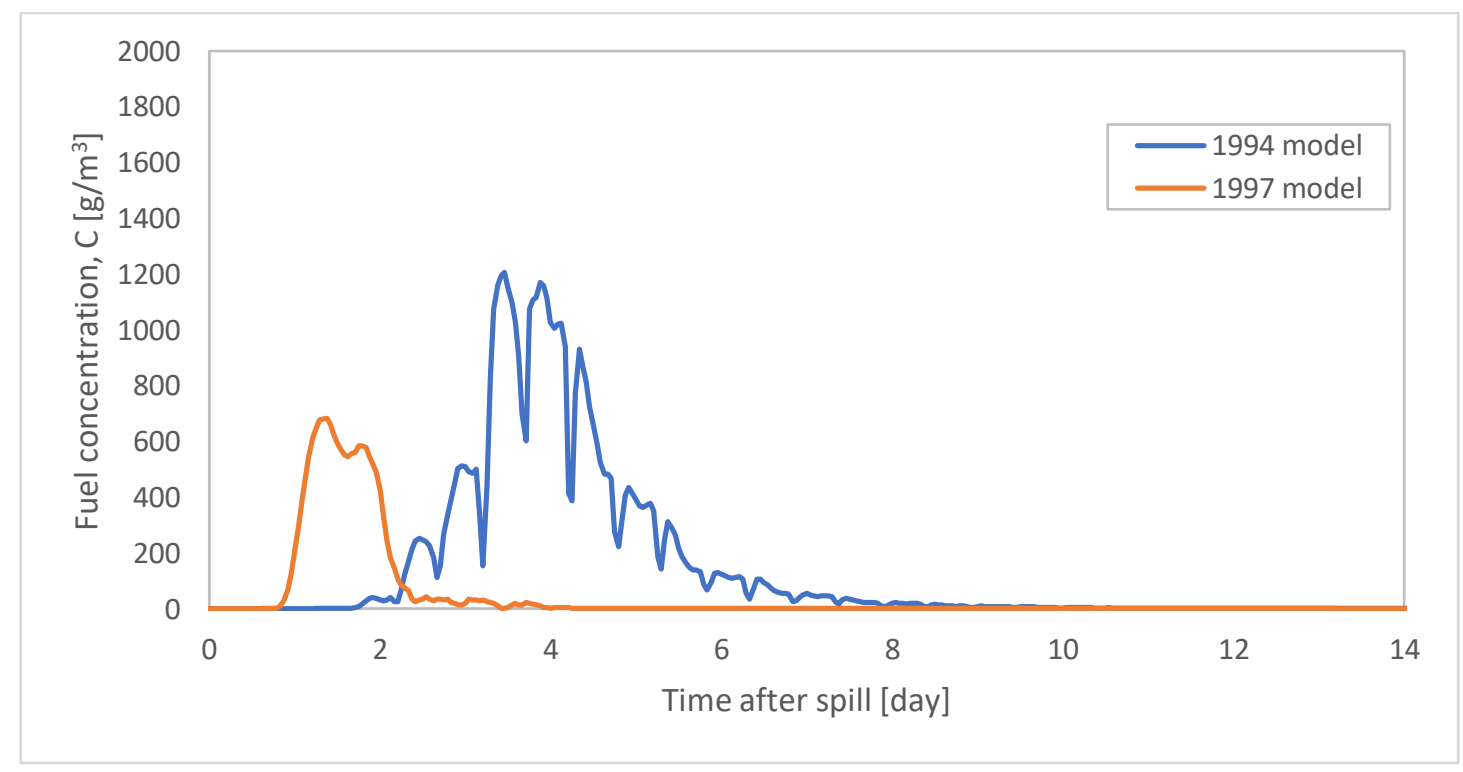

Figure 16: 1-day spill duration at St. Helens, OR (seg. 276) in the Columbia River. 


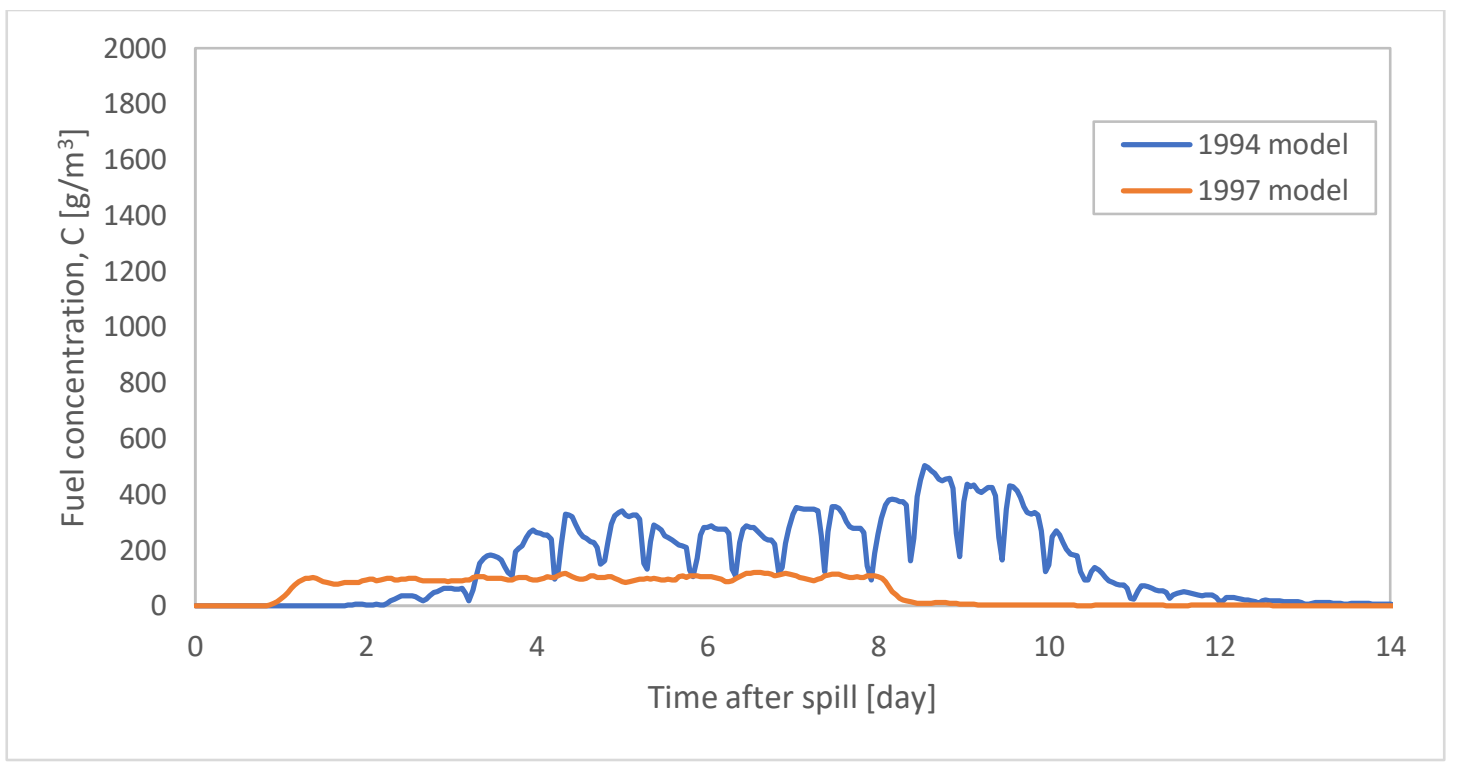

Figure 17: 1-week spill duration at St. Helens, OR (seg. 276) in the Columbia River.

The fuel concentrations for the low flow model year exhibited very prominent fluctuations due to tidal influence. For all scenarios, the plume arrived approximately two days after the spill began. The 1-hour spill reached a maximum concentration of $1,430 \mathrm{~g} / \mathrm{m}^{3}$ within 12 hours of first arriving and then slowly decreased over nearly five days. The 1-day plume increased more slowly after arriving reaching a maximum concentration of $1,210 \mathrm{~g} / \mathrm{m}^{3}$ after approximately one day, then decreasing similarly to the 1-hour spill but at a slower rate. The concentration for the 1week spill had similar behavior to the plume in the Willamette River reaching a maximum of 500 $\mathrm{g} / \mathrm{m}^{3}$ after 8 days.

\subsubsection{Rainier, $O R$ (seg. 322)}

Model segment 322 is located just prior to the town of Rainier, OR in the Columbia River.

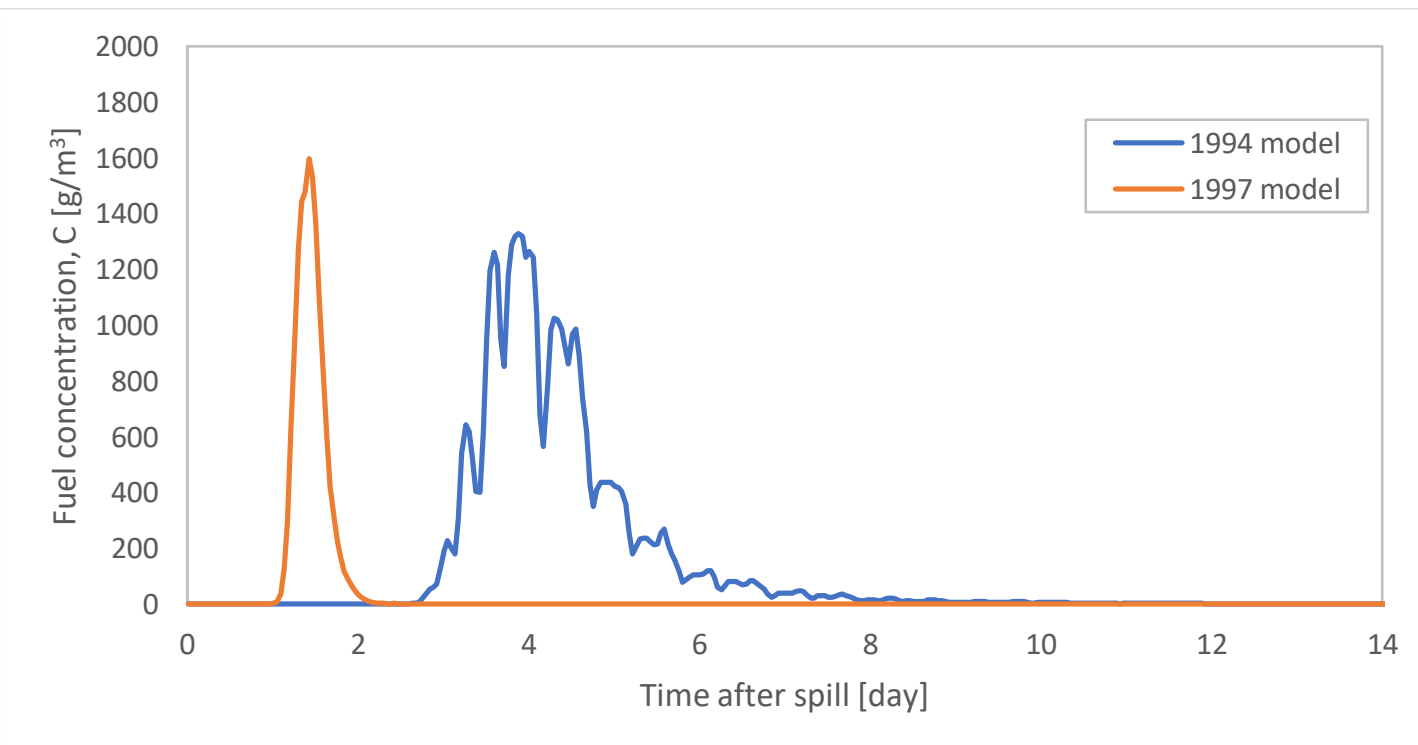

Figure 18: 1-hour spill duration at Rainier, OR (seg. 322) in the Columbia River. 


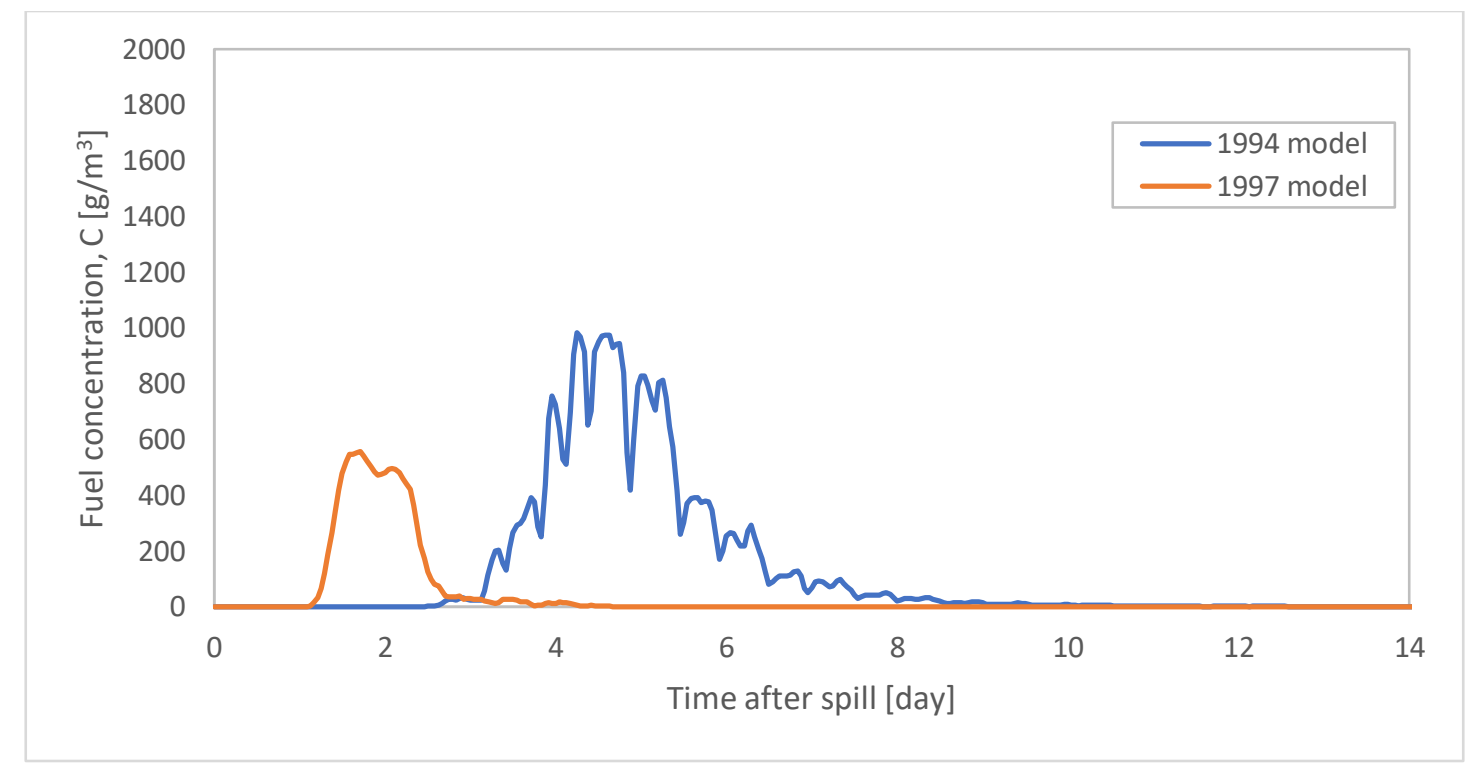

Figure 19: 1-day spill duration at Rainier, OR (seg. 322) in the Columbia River.

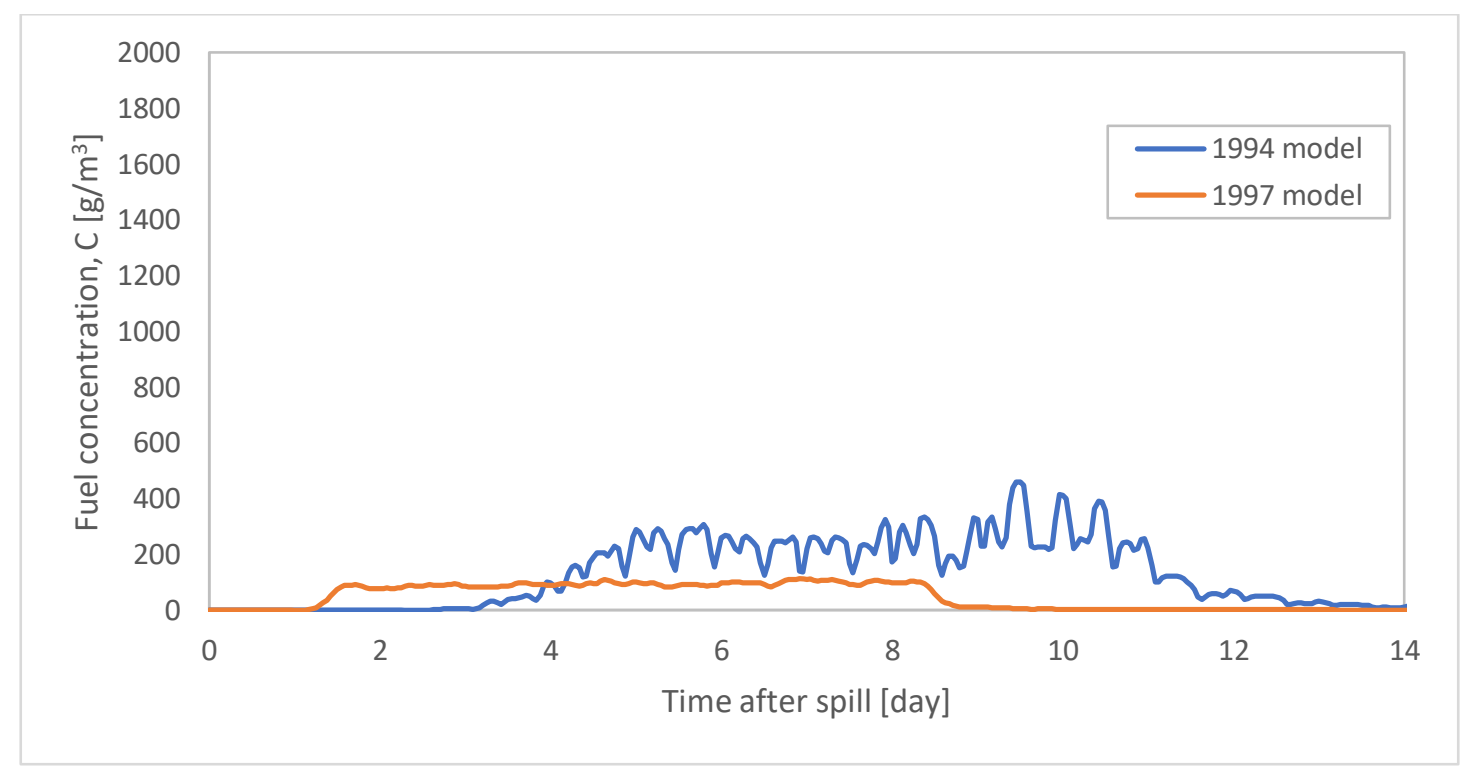

Figure 20: 1-week spill duration at Rainier, OR (seg. 322) in the Columbia River.

The 1-hour (Figure 18) and 1-day (Figure 19) plume behaviors were nearly identical to those at St. Helens for both model years. Similarly, the high flow year behavior for the 1-week (Figure 20) was nearly the same. The low flow year for the 1-week spill appeared to be much more sensitive to tidal fluctuations. The low flow year plumes arrived almost three days after the spills began, and the high flow year plumes arrived in just over 1 day. The high flow year maximum concentrations were $1600 \mathrm{~g} / \mathrm{m}^{3}, 615 \mathrm{~g} / \mathrm{m}^{3}$, and $115 \mathrm{~g} / \mathrm{m}^{3}$ for modeled spill durations of 1-hour, 1day, and 1-week, respectively. The corresponding low flow year maximum concentrations were $1,330 \mathrm{~g} / \mathrm{m}^{3}, 1,050 \mathrm{~g} / \mathrm{m}^{3}$, and $450 \mathrm{~g} / \mathrm{m}^{3}$. 


\subsubsection{Beaver Army Terminal (model terminus; seg. 356)}

Model segment 356 is the terminus for the Lower Willamette River models located at Beaver Army Terminal near Quincy, OR.

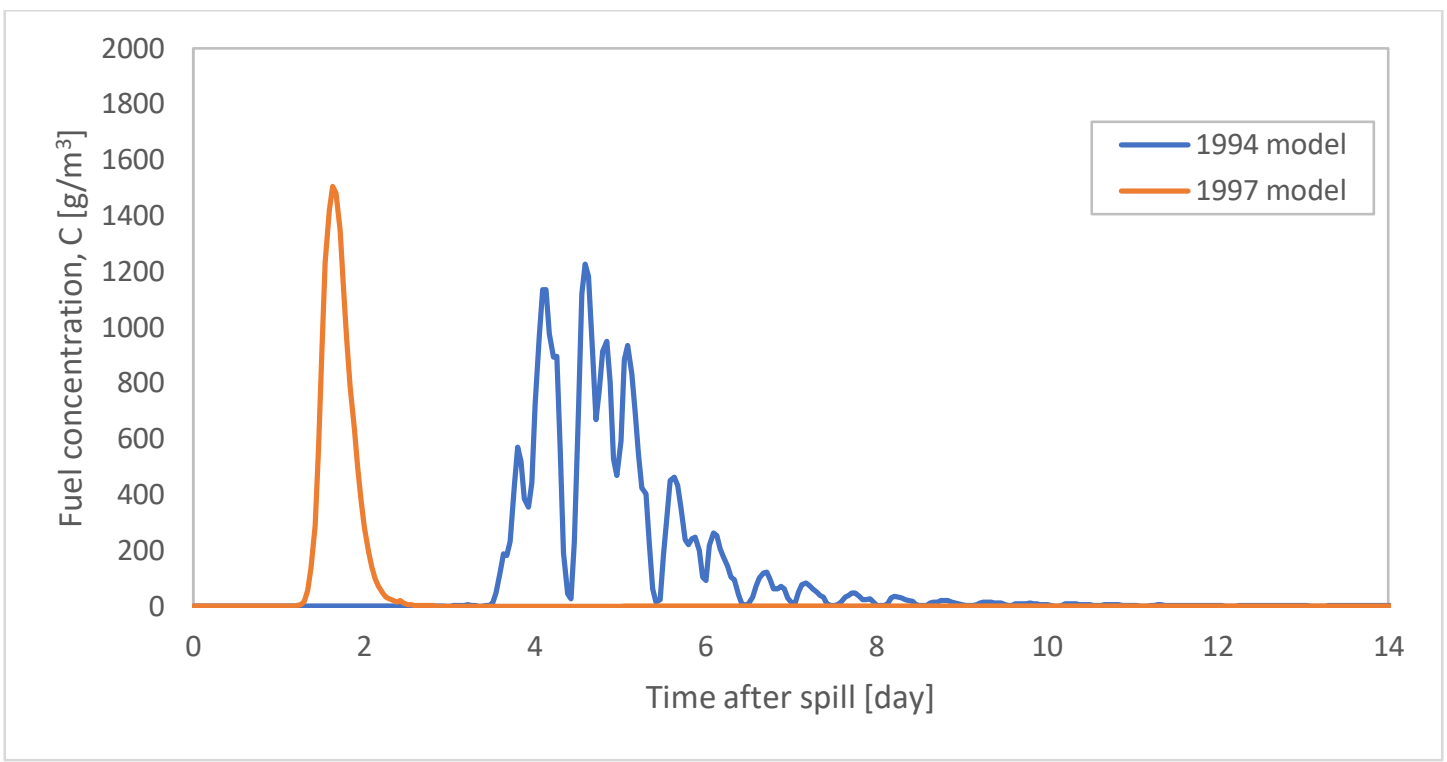

Figure 21: 1-hour spill duration at Beaver Army Terminal (seg. 356), near Quincy, OR, in the Columbia River.

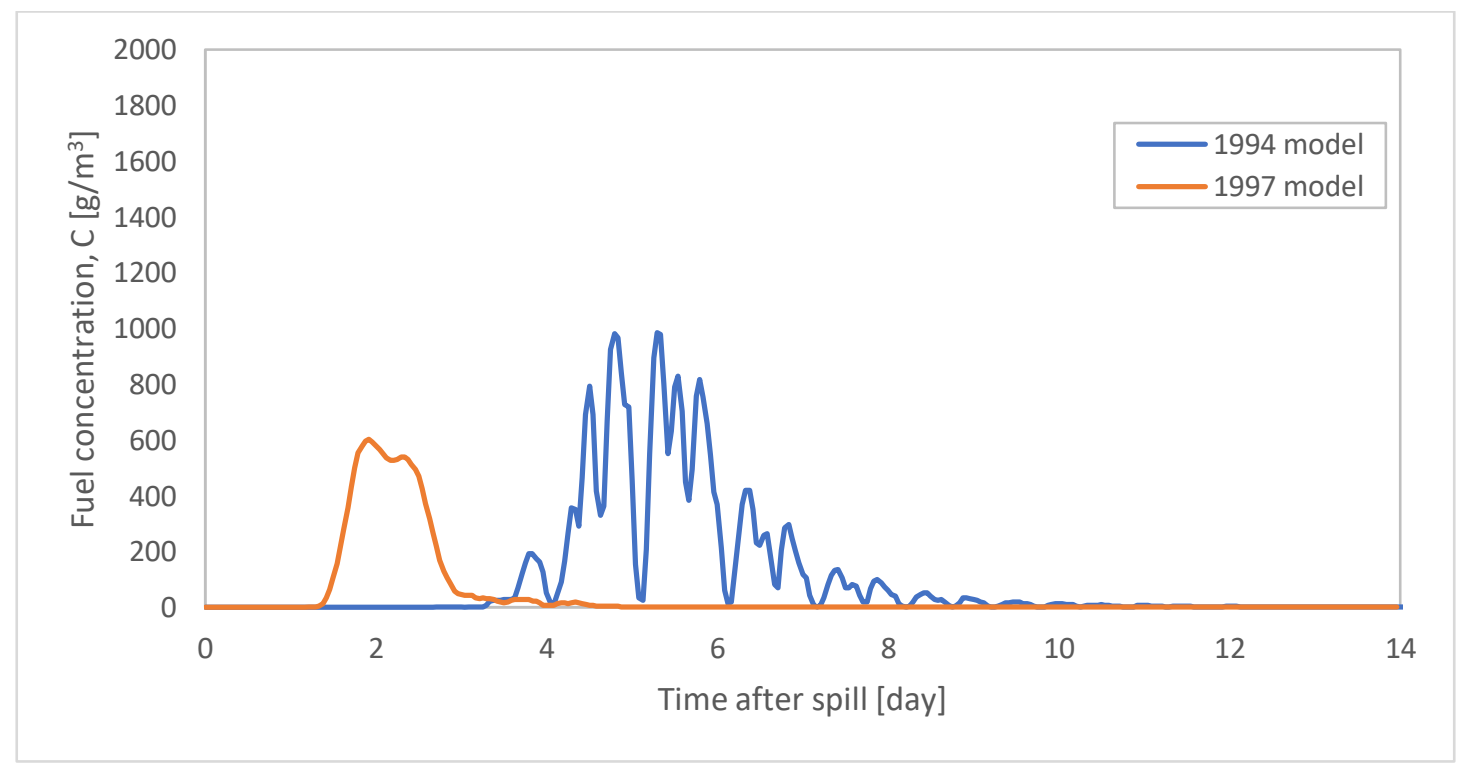

Figure 22: 1-day spill duration at Beaver Army Terminal (seg. 356), near Quincy, OR, in the Columbia River. 


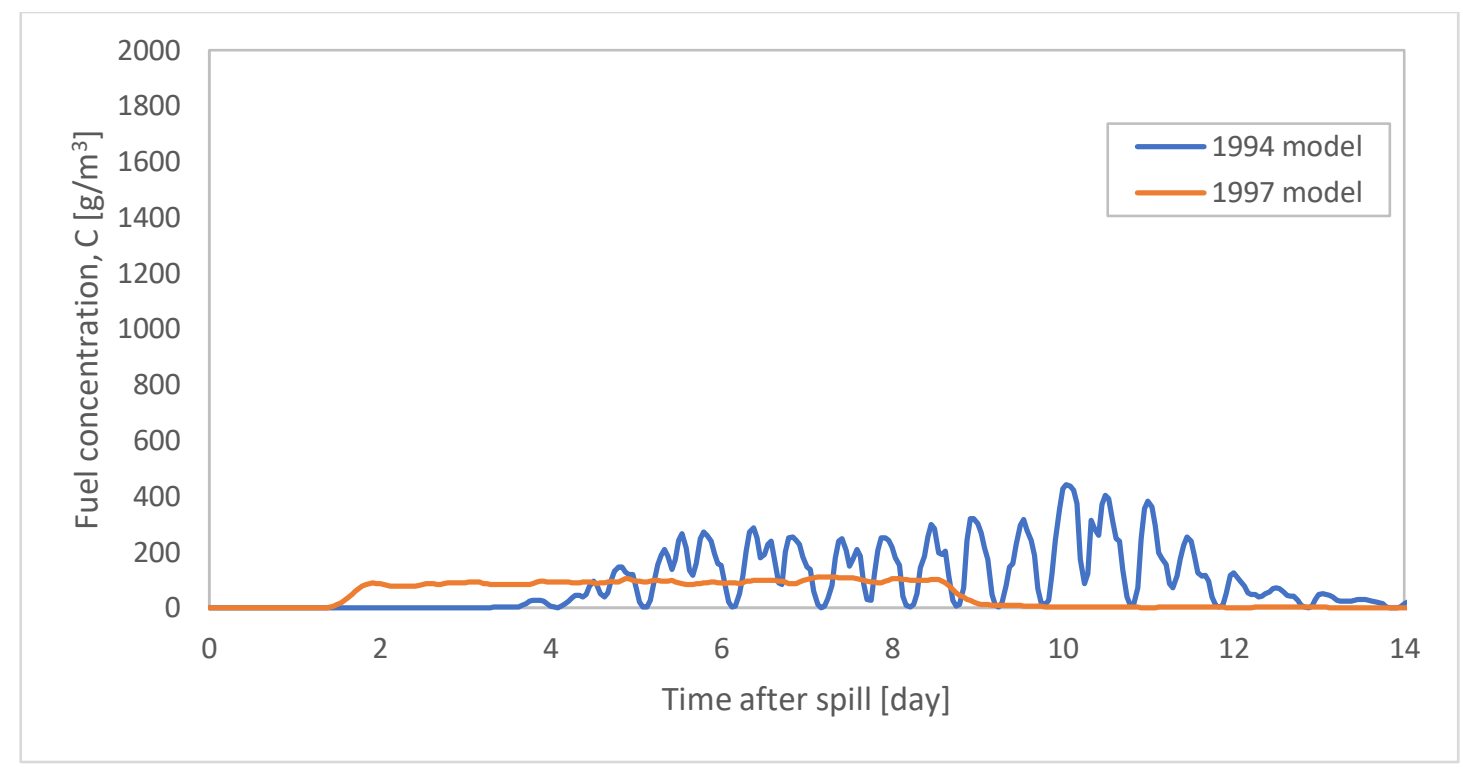

Figure 23: 1-week spill duration at Beaver Army Terminal (seg. 356), near Quincy, OR, in the Columbia River.

The plume behaviors for the high flow model year are nearly identical to the upstream Columbia River segments. The general trends for the low flow model year are consistent with upstream segments, however there are significant differences. Concentration levels drop to zero at what corresponded to tidal fluctuations in upstream segments. This is likely due to how the model handles boundary conditions, such as concentrations flowing out of the system which are removed. Thus, when upstream flows might occur as a result of tidal head fluctuations, water with no fuel concentration flows back into the model.

\section{Discussion}

Model sensitivities were analyzed to determine possible experimental errors and refinements as well as implications of spill behavior. Additionally, water quality results were analyzed as Rainier, OR to determine how long the town would be unable to access a major drinking water source, the Columbia River.

\subsection{Model sensitivity}

For both model years 1997 and 1994 as well as each of the spill scenarios, nearly all of the fuel spill plume traveled down the Multnomah Channel (Figure 24). Comparing results for the 1-day spill durations, the maximum concentrations at the confluence of the Willamette and Columbia Rivers was less than $1 \mathrm{~g} / \mathrm{m}^{3}$ for the low flow model year and $135 \mathrm{~g} / \mathrm{m}^{3}$ for high flow model year. Interestingly, the maximum concentrations after the inflow to the Multnomah Channel and before the confluence (seg. 105; Figure 4) were 0.523 and $4210 \mathrm{~g} / \mathrm{m}^{3}$ for the low and high flow years, respectively. This indicates that the flow in that span of the Willamette River might recirculate and have very low discharge rates into the Columbia River. Annual discharge rate data was not available for the Multnomah Channel for the model years so the spill behavior could not be verified. Further investigation into why this modeled spill behavior occurred could yield more conclusive predictive information. 


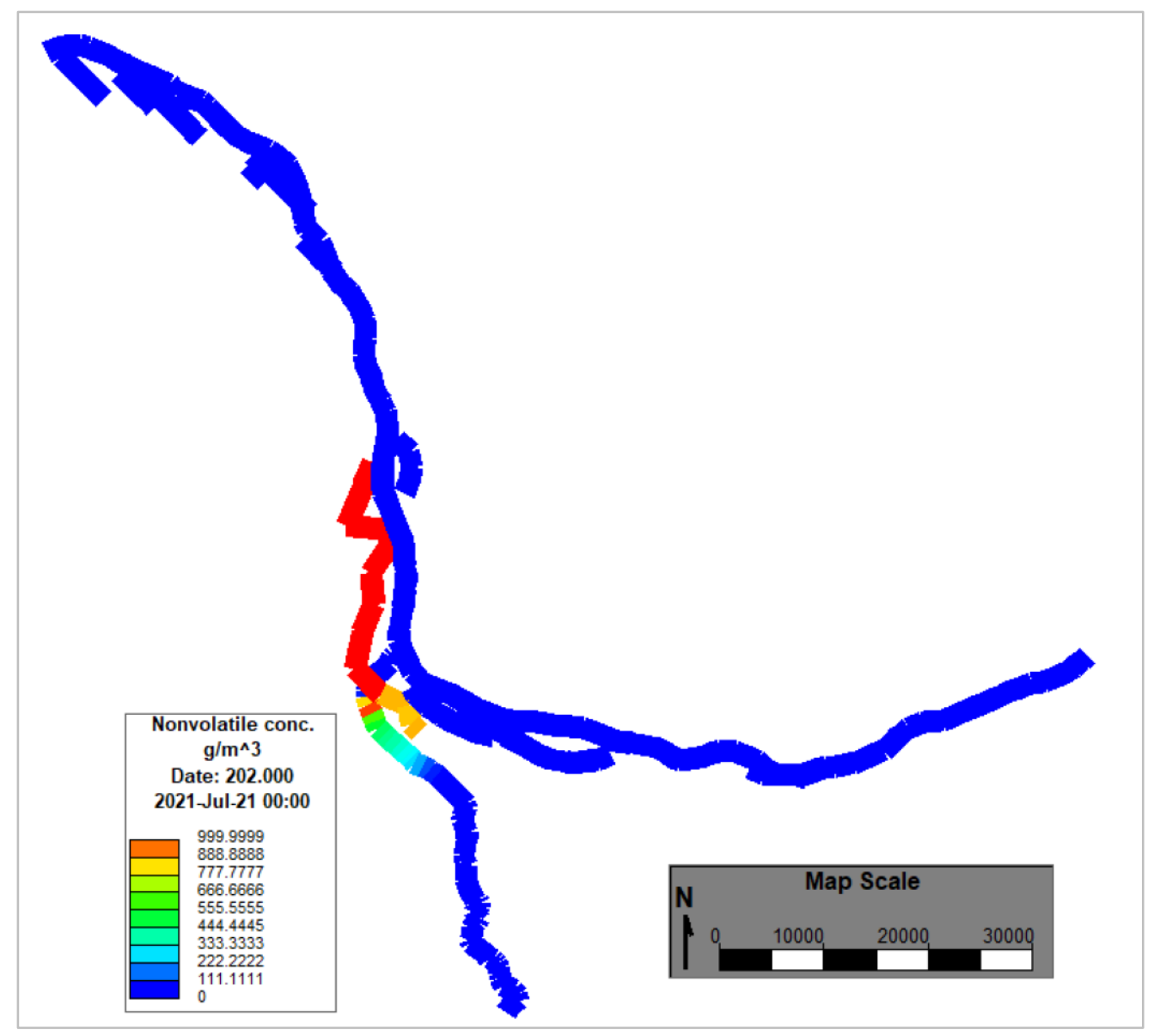

Figure 24: Plan view of the modeled system for the 1-day spill duration, Julian day 202.0 (5 days after spill begins), model year 1994.

\subsection{Vertical mixing}

Liquid fuels are less dense than water before environmental exposure, and thus float at the surface as a slick initially after a spill (Dew et al., 2015; Shen and Yapa, 1988). Fuel slick do degrade over time due to evaporation/dissolution of volatiles, UV exposure, sedimentation and sediment mixing (Figure 3). These processes typically occur hours-to-months after a spill. Though vertical mixing in the water column does occur when fuel slicks pass through locks, waterfalls, and other structures that create turbulent eddies (Clark et al., 1990) no such structures exist on the water bodies over the domain of the modeled spill.

A profile of the model Willamette River branch taken from the 1-day spill duration, Julian day 203 (6 days after the spill initialized), model year 1994 (Figure 25), shows that the fuel spill is vertically well mixed in the water column in many areas. This trend was consistent for each of spill scenario and model year, and vertical mixing occurred immediately after the spill initialized. This was a result of neglecting the buoyancy of the fuel concentrations in the CEQUAL-W2 control files. This can be modified by providing a negative settling velocity for the conservative (NON-VOC) and volatile (VOC) fractions in the Generic Constituent section of the $\mathrm{W} 2$ control file. Because these fractions were generalized and simplified, trial and error might be necessary to replicate realistic settling characteristics. 


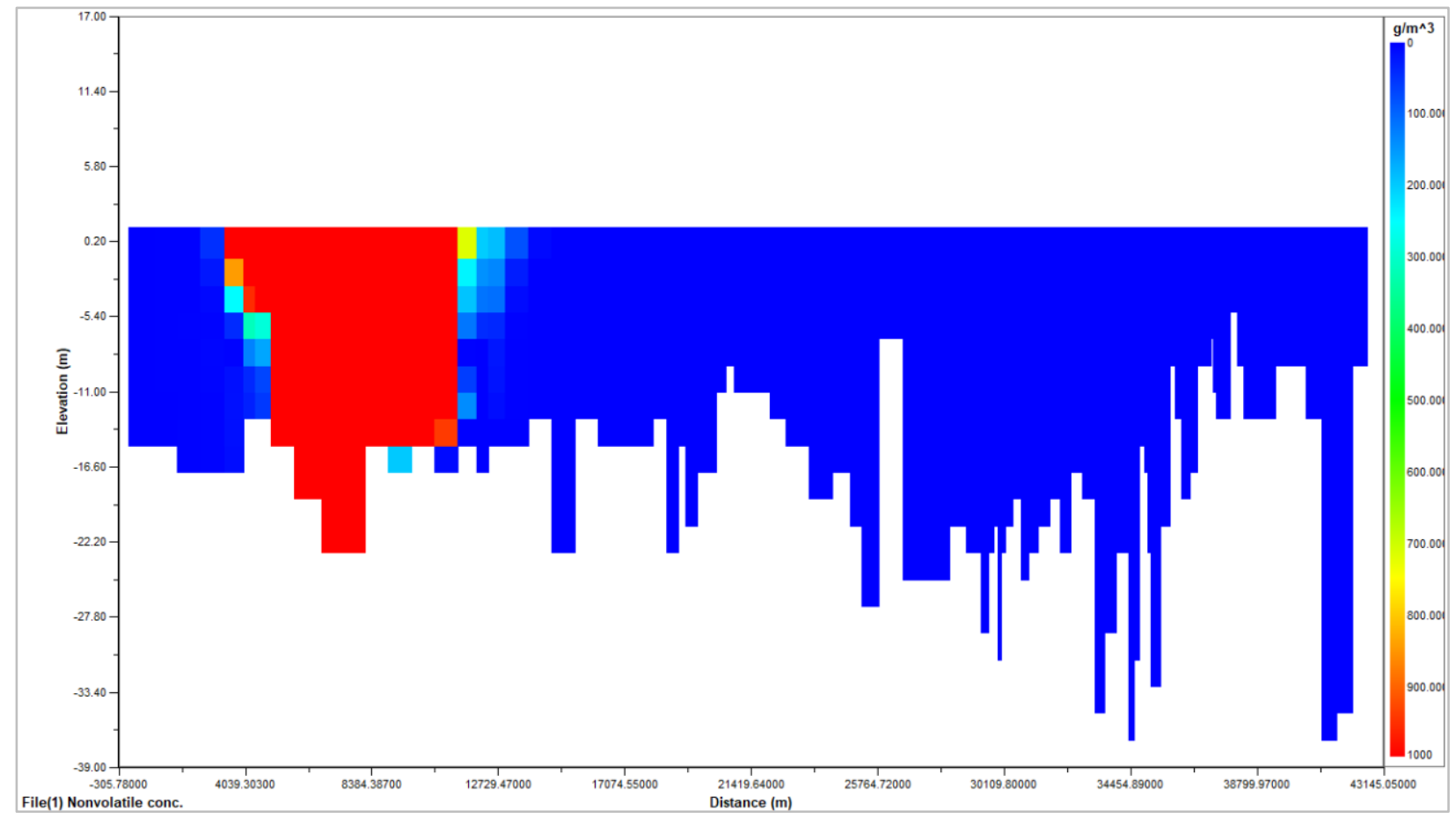

Figure 25: Profile view of Willamette River model (branch 2) for the 1-day spill duration on Julian Day 202 (5 days after spill begins), model year 1994.

Furthermore, when examining the fuel concentrations for each downstream segment, which were measured at the water surface (see Results), one noticeable trait is the area under the curves diminish substantially for progressive segments. Though volatilization accounts for some of this, it does not explain the degree of loss of mass observed. This apparent loss of mass is directly linked to the vertical mixing and the volume of each segment. As the model segment volumes increase dramatically from the Willamette to the Columbia River, the vertical mixing of the fuel concentration fractions into the water column decreased the concentration at the water surface. As the plume progress downstream, in addition to volume fluctuations, riverbed shear, Manning's coefficients, and other drag forces likely contribute to the apparent loss of mass. This issue would be largely fixed with the adjustments of the generic constituent settling rates.

\subsection{Water quality at Rainier, OR (seg. 322)}

Unlike the other cities in proximity to the model segments analyzed, the town of Rainier, OR sources its drinking water, secondarily, from the surface water of the Columbia River (DEQ, 2000). Thus, modeled water quality data were analyzed in addition to the fuel concentrations.

EPA recommends that benzene limits for drinking water are $0 \mathrm{mg} / \mathrm{l}$, with a maximum allowable limit of $0.005 \mathrm{mg} / \mathrm{l}$ (or $0.005 \mathrm{~g} / \mathrm{m}^{3}$ ) (2021). Because Rainier, OR sources its drinking water from the Columbia River surface water, water quality analysis was performed in addition to fuel concentration comparisons. As stated in section 3.2, a simplifying assumption that all VOCs were generalized as a single mass was made since the actual quantities of constituents were unknown. Per EPA guidelines (2021), benzene is the limiting constituent of those determined in the literature review. Thus, time intervals for total VOC concentrations above the $0.005 \mathrm{~g} / \mathrm{m}^{3}$ 
threshold were determined to estimate how long access to Rainier's water supply would be disrupted.

The low discharge model year VOC levels exceeded the limit after approximately 2.5 days and remained above the limit for 12.4 days, 12.8 days, and 18.1 days for the 1-hour, 1-day, and 1week spills, respectively. The high discharge year VOC levels exceeded the limit approximately one day after the spill and remained above the limit for 1.8 days, 7.3 days, and 12.3 days for the corresponding spills. However, the vertical mixing of the plume into the water column - as discussed in section 5.4 - likely impacted these results. Therefore, the limit exceedance intervals may change with future model refinements.

\section{Conclusions}

The low flow model year 1994 had high sensitivity to tidal fluctuations, frequently resulting in upstream (negative velocity/flow rate) flows. Overall, this greatly impacted the fuel

concentrations for the three spill duration scenarios leading to prolonged residence times. These residence times extended for several days after the end of the spill for each of the scenarios and analyzed segment. Moreover, the fuel concentrations remained relatively high during the peak concentration intervals. These factors led to negative water quality impacts for downstream communities that rely on the Columbia River for drinking water for between 12-18 days.

The high flow model year 1997 had nominal sensitivity to tidal fluctuations overall resulting in solely positive, unidirectional flows. The fuel concentrations were transient, rapidly decreasing in each analyzed segment shortly after each spill duration terminated. The spills had much lower concentrations than the low flow counterparts, with the exception of the 1-hour spill which behaved as a high concentration front. This was due to significantly larger flow rates and volumes for the 1997 model year and the vertical mixing of the fuel plume into the water column. With an adjusted settling velocity, the areas under the curves for both modeled years would likely be comparable. The overall water quality impacts for the high flow year model scenarios were typically much shorter in duration than the low flow year but still impacted drinking water for downstream communities for between 2-12 day.

This study was a preliminary attempt at modeling a catastrophic fuel spill from the CEI Hub following a Cascadia earthquake event. Though the results were useful in creating a framework for modeling and predicting the fuel concentrations and water quality implications for such a spill, many refinements should be made to the models developed herein. Future recommendations for refining the models used in this study are as follows:

- Buoyancy - adjust the settling velocities (negative values) for the conservative (NONVOC) and volatile (VOC) fractions in the generic constituent section of the CE-QUAL$\mathrm{W} 2$ control file. This will likely require some trial and error, however, a settling velocity of $-0.1 \mathrm{~m} / \mathrm{s}$ may be a reasonable starting place.

- Variable spill rates and volumes - more realistic scenarios would include variable spill rates and volumes instead of the constant spill rates assumed for the models used in this study. 
- Sedimentation/sediment transport - literature reviewed for this study indicated that sediment interaction with fuel droplets and particle greatly influence long term spill behavior - including the formation of OPAs - and environmental impacts. CE-QUALW2 does not currently have sediment transport modeling capabilities. It may be possible to link existing sediment transport models with CE-QUAL-W2 to investigate the impacts of OPA sedimentation and transport.

- Dissolution versus evaporation - the current source/sink terms included in the Generic Constituent card of the CE-QUAL-W2 model does not include dissolution rates, thus loss of mass tends to occur from 0 th and 1 st-order decay rates and evaporation. The literature reviewed for this study frequently focused on the dissolution of volatile constituents into the water column. This would likely have significant implications for water quality analysis after fuel spills.

- Varying ratios of liquid fuels - as more information related to the types and quantities of fuels stored at the CEI Hub becomes available, model spill scenarios can be refined using specific fuel types and ratios. Varying these ratios based on proximities to containment berms and the river, as well as different spill rates might create a more refined prediction.

Further investigations into model flow behavior in the Multnomah Channel, the confluence of the Willamette and Columbia Rivers, and the section of the Lower Willamette River between them is also recommended. Determining whether there is an error in the model or unusual flows in that section of the Willamette River will be beneficial for future analysis. 


\section{References}

Berger, C., Annear Jr., R. L., and Wells, S. A. (2001). Lower Willamette River model: Model calibration, Technical report, Department of Civil Engineering, Portland State University, Portland, OR.

Berger, C. J., and Wells, S. A. (2019). Impact of wastewater treatment discharge to the Willamette River: Hydrodynamic and water quality model updates, Water Quality Research Group, Department of Civil and Environmental Engineering, Portland State University, Portland, OR.

Chin, J. Y., and Batterman, S. A. (2012). "VOC composition of current motor vehicle fuels and vapors, collinearity analyses for receptor modeling." Chemosphere, 86(9), 951-958.

Clark, R. M., Goodrich, J. A., Vicory, A. H., (1990). "The Ohio River oil spill: A case study." American Water Works Association, 39-44.

Department of Environmental Quality (DEQ), "Source water assessment summary brochure," Rainier Water Department, 2000.

Dew, W. A., Hontel, A., Rood, S. B., Pyle, G. G. (2015). "Biological effects and toxicity of diluted bitumen and its constituents in freshwater systems." J. Appl. Toxicol. 35, 12191227.

Engineering ToolBox. (2003). "Fuels - Densities and Specific Volume." Engineering ToolBox, <https://www.engineeringtoolbox.com/fuels-densities-specific-volumes-d_166.html> (Jan. 15, 2021).

Environmental Protection Agency (EPA). "Groundwater and drinking water: National primary drinking water regulations." United States Environmental Protection Agency, Last modified January 5, $2021<\mathrm{https}$ //www.epa.gov/ground-water-and-drinkingwater/national-primary-drinking-water-regulations $>$

Goldfinger, C., Nelson, C. H., Morey, A. E., Johnson, J. E., Patton, J. R., Karabanov, E. B., Gutierrez-Pastor, J., Eriksson, A. T., Gracia, E., Dunhill, G., Enkin, R. J., Dallimore, A., and Vallier, T. (2012) "Turbidite event history - Methods and implications for holocene paleoseismicity of the Cascadia Subduction Zone." U.S. Geol. Surv. Prof. Paper 1661-F, 170.

Hayter, E., McCulloch, R., Redder, T., Boufadel, M., Johnson, R., Fitzpatrick, F. (2015) "Modeling the transport of oil particle aggregates and mixed sediment in surface waters." US Army Corps of Engineers, Engineer Research and Development Center, Missouri, 111.

Hibbs, D. E., Gulliver, J. S., Voller, V. R., Chen, Y. F. (1999). "Processes controlling aqueous concentrations for riverine spills.” J. Hazard. Mat. A 64, 57-73.

Njobuenwu, D.O., Amadi, S.A. and Ukpaka, P.C. (2005). "Dissolution Rate of BTEX Contaminants in Water.” Can. J. Chem. Eng., 83, 985-989. 
Oregon Seismic Safety Policy Advisory Commission (OSSPAC). (2019). "Regulating liquid fuel tanks." CEI Hub mitigation strategies: Increasing fuel resilience to survive Cascadia, OSSPAC Publication Number 19-01, Oregon, 8-9.

Shen, H. T., and Yapa, P. D. (1988). “Oil slick transport in rivers.” J. Hydraul. Eng., 114(5), 529-543.

Trusek-Holwnia, A. and Noworyta, A. (2015). “Two-step treatment of harmful industrial wastewater: An analysis of microbial reactor with integrated membrane retention for benzene and toluene removal." Polish J. Chem. Tech., 17(4), 15-22.

Wang, Y., Bartlett, S. F., and Miles, S. B. (2013) "Earthquake risk study for the Critical Energy Infrastructure Hub in Oregon.” Oregon Dept. Geol. and Miner. Ind., Portland, OR, OpenFile Report 0-13-9.

Wells, S. A., Editor (2019a) "CE-QUAL-W2: A two-dimensional, laterally averaged, hydrodynamic and water quality model, version 4.2, user manual part 1, introduction, model download package, how to run the model," Department of Civil and Environmental Engineering, Portland State University, Portland, OR.

Wells, S. A., Editor (2019b) "CE-QUAL-W2: A two-dimensional, laterally averaged, hydrodynamic and water quality model, version 4.2, user manual part 2, theory," Department of Civil and Environmental Engineering, Portland State University, Portland, OR.

Wells, S. A., Editor (2019c) "CE-QUAL-W2: A two-dimensional, laterally averaged, hydrodynamic and water quality model, version 4.2, user manual part 3, input and output files," Department of Civil and Environmental Engineering, Portland State University, Portland, OR. 